\title{
AN EXAMINATION OF SOME SHRINKAGE ESTIMATORS FOR DIFFERENT SAMPLE SIZES AND CORRELATION STRUCTURES IN THE LINEAR REGRESSION
}

\author{
MERAL EBEGİI
}

\begin{abstract}
In the regression analysis, if there happens to be some kind of relation (multicollinearity) between independent variables, the Least Squares (LS) estimation method may lead to the use of wrong models and hence to wrong findings out of the model. Some methods have been developed to solve this problem; one of which is the "biased estimation method". In this study, a test statistics for Ridge and Liu estimators that are kinds of Shrinkage biased estimators is analyzed. Ridge and Liu estimators are examined via simulation study by the use of this test statistics, in terms of different correlation coefficients between the independent variables and different sample sizes..
\end{abstract}

\section{INTRODUCTION}

In the multiple linear regression analysis, if multicollinearity occurs between independent variables, the LS estimation method may lead to of wrong models and hence to wrong findings out of the model. Various methods have been devised in order to carry out regression analysis with such independent variables which exhibit dependence on each other. One of such methods is the biased estimation method. Most widely used biased estimation methods are; Principal Components regression, Ridge regression and their variations. Estimations related to biased methods are more biased than the LS estimators are- when compared, but they produce less variance estimations. Main purpose of biased estimation methods is to make variance area smaller for an exchange of small side, which is quite large at the LS estimation method. Therefore, more results that are valid can be obtained by comparing with the LS method.

One of the estimators under the scope of biased estimators is named as Shrinkage estimators. Principal Components regression, Ridge regression and their derivatives

Received by the editors Nov. 01, 2007; Accepted: Sept. 05, 2008

2000 Mathematics Subject Classification. Primary 62J05, 62J07.

Key words and phrases. Linear Admissible Estimators, Mean Square Error, Central-F Approximations, Shrinkage Estimators. 
are also part of this type. Farebrother (1978) formed a general structure for Shrinkage estimators. He placed Ridge, Principal Components and conditioned-minimum mean error square biased estimators under this structure and elaborated that these are each Shrinkage estimators [1]. Liski (1982) proposed the powerful Mean Square Error (MSE) as criteria to choose between LS estimator and Shrinkage estimator [2]. Liski (1983) also used the weak MSE test to make a choice between LS estimator and shrinkage estimator [3]. Kejian (1993) suggested the Liu- Kejian estimator as an alternative to the Ridge estimator [4]. Later, this estimator is named as "Liu estimator" by Akdeniz and Kaçıranlar (1995) [5]. Then, Akdeniz and Erol (2003) considered the comparison of some Shrinkage estimators and gave a numerical example [6]. Ebegil et al. (2006) compared various Shrinkage estimators with the help of a simulation study under different correlation coefficients [7].

The second section of this study examines the basic structure of Shrinkage estimators. Keeping this information in mind, by comparing the MSE matrix of LS estimators and Shrinkage estimators, their condition of necessary and sufficiency were stressed. In accordance with a test statistics gathered from this condition, hypothesis test was examined.

In the last section, a simulation study is carried out by a MATLAB. As a result of simulation study for different correlation coefficients and sample sizes, Ridge and Liu estimators which are constructed to hypothesis test were compared by constructing rejection and acceptation regions and the results were interpreted.

\section{SHRINKAGE ESTIMATORS AND MEAN SQUARE ERROR MATRICES}

Consider general linear regression model as [1]

$$
Y=X \beta+\varepsilon, \quad \varepsilon \sim\left(0, \sigma^{2} I_{n}\right), \operatorname{rank}\left(X_{n \times q}\right)=q \leq n
$$

where $Y$ is an $(n \times 1)$ dimensional vector of dependent variable, $\mathrm{X}$ is an $(n \times q)$ dimensional non-stochastic input matrix of observations $(q=k+1), \beta$ is a $(q \times 1)$ dimensional vector of unknown regression coefficients, $\varepsilon$ is a vector of randomly distributed errors satisfying $\mathrm{E}(\varepsilon)=0$ and $\mathrm{E}\left(\varepsilon \varepsilon^{\prime}\right)=\sigma^{2} I_{n}$.

General linear estimators are described in the following form. Here, C and c are a matrix and a vector respectively.

$$
\widetilde{\beta}=C Y+c
$$

This estimator can be named as the linear estimator of $\beta$ [8]. In equation (2.2), when $C=\left(X^{\prime} X\right)^{-1} X^{\prime}$ and $\mathrm{c}=0$ are placed, a special condition of the estimator is formed as follows;

$$
\widehat{\beta}=\left(X^{\prime} X\right)^{-1} X^{\prime} Y .
$$


This estimator is called LS estimator of $\beta$.

Alternative estimators considered under the model equation (2.1), the form in equation (2.2) are of the form

$$
\widetilde{\beta}=A \widehat{\beta}+d
$$

where, $\mathrm{A}$ and $\mathrm{d}$ are a $(q \times q)$ dimensional matrix and a $(q \times 1)$ dimensional vector of constants respectively.

When determining the best estimator from among the unbiased estimators, the one with the minimum variance is preferred. When biased estimators are concerned, the MSE is used for determining the best estimator. This is because biased and unbiased estimators can be identified by checking the MSE matrices [7]. The MSE matrix is defined as

$$
\operatorname{MSE}(\widetilde{\beta})=E(\widetilde{\beta}-\beta)(\widetilde{\beta}-\beta)^{\prime}
$$

The MSE matrix can be written for scalar risk

$$
\operatorname{MSE}(\widetilde{\beta}, C)=E(\widetilde{\beta}-\beta)^{\prime} C(\widetilde{\beta}-\beta) .
$$

The matrix $\mathrm{C}$ is a $(k \times k)$ dimensional nonnegative defined (n.n.d.) symmetrical matrix.

Suppose that two estimators are given as $\widetilde{\beta}_{1}$ and $\widetilde{\beta}_{2}$. When these estimators compare, $\widetilde{\beta}_{1}$ estimator is said to be better than $\widetilde{\beta}_{2}$ under the MSE in equation (2.4) if $M S E\left(\widetilde{\beta}_{2}\right)-M S E\left(\widetilde{\beta}_{1}\right)$ is n.n.d. for all $\beta$, and for some $\beta, M S E\left(\widetilde{\beta}_{2}\right)-$ $\operatorname{MSE}\left(\widetilde{\beta}_{1}\right)$ is not zero. In other words, for the matrix differences we have,

$$
\begin{aligned}
& \text { for all } \beta \text { we have } \operatorname{MSE}\left(\widetilde{\beta}_{2}\right)-\operatorname{MSE}\left(\widetilde{\beta}_{1}\right) \geq 0 \text {, and, } \\
& \text { for some } \beta \text { we have } \operatorname{MSE}\left(\widetilde{\beta}_{2}\right)-\operatorname{MSE}\left(\widetilde{\beta}_{1}\right) \neq 0 \text {. }
\end{aligned}
$$

Where the estimator $\widetilde{\beta}_{1}$ is said to be better than $\widetilde{\beta}_{2}$ with respect to MSE in equation (2.4) [2], [3],[7].

An estimator $\widetilde{\beta}$ is said to be admissible, if no estimator exists which dominates it. In general, for the class of all linear estimator $\widetilde{\beta}=C Y+c$, admissibility depends on a given estimator class. Admissibility is defined in terms of the MSE of $\widetilde{\beta}$ in equation (2.4).

Definition 2.1. Consider the conditions:

$$
\text { for all } \beta \text { we have } M S E(\widetilde{\beta})-M S E(\widehat{\beta}) \geq 0 \text {, and, }
$$




$$
\text { for some } \beta \text { we have } M S E(\widetilde{\beta})-M S E(\widehat{\beta}) \neq 0 \text {. }
$$

If these conditions are satisfied for all the estimators $\widetilde{\beta}$ then the estimator $\widehat{\beta}$ is said to be admissible for the MSEs.

For admissibility, the form of the estimator $\beta$ is as follows [2],[10].

$$
\widetilde{\beta}=A(\widehat{\beta}-b)+b .
$$

In equation (2.8), $\mathrm{A}$ is a $(q \times q)$ dimensional matrix and $\mathrm{b}$ is a constant vector. Estimators defined by this way belong to the class of linear admissible estimators. Other conditions for admissibility are

$$
\left(X^{\prime} X\right) A \text { or } A\left(X^{\prime} X\right)^{-1} \text { is symmetric }
$$

$$
\text { and }
$$

$$
\text { the eigenvalues of } A \text { lie in }[0,1] \text {. }
$$

Since $X^{\prime} X$ and $\mathrm{A}$ are symmetric, there exists a $(q \times q)$ orthonormal matrix $\mathrm{P}$ such that $\mathrm{P}^{\prime} X^{\prime} X P=\Lambda$ is a $(q \times q)$ diagonal matrix. The diagonal elements $\lambda_{1}, \lambda_{2}, \cdots, \lambda_{q}$ of the $\Lambda$ matrix are the eigenvalues of $X^{\prime} X$, which are assumed in a decreasing order. Also, $\mathrm{P}^{\prime} A P$ is a diagonal matrix whose diagonal elements $\delta_{1}, \delta_{2}, \cdots, \delta_{q}$ lie in $[0,1][2],[11]$.

Model equation (2.1) can be written in a canonical form

$$
Y=X P P^{\prime} \beta+\varepsilon=Z \alpha+\varepsilon,
$$

where $\mathrm{Z}=\mathrm{XP}$ and $\alpha=P^{\prime} \beta$. The admissible estimators of $\alpha$ are of the form

$$
\widetilde{\alpha}=P^{\prime} A(\widehat{\beta}-b)+P^{\prime} b=P^{\prime} A P(\widehat{\alpha}-a)+a=\Delta(\widehat{\alpha}-a)+a,
$$

where $\widehat{\alpha}=P^{\prime} \widehat{\beta}$ is $a=P^{\prime} b$. These kind of admissible linear estimators are called Shrinkage estimators.

The MSE matrices of the estimators $\widehat{\beta}$ and $\widetilde{\beta}$ are respectively [2],

$$
\begin{gathered}
M S E(\widehat{\beta})=\sigma^{2}\left(X^{\prime} X\right)^{-1}, \text { and } \\
M S E(\widetilde{\beta})=\sigma^{2} A\left(X^{\prime} X\right)^{-1} A^{\prime}+(I-A)(\beta-b)(\beta-b)^{\prime}(I-A) .
\end{gathered}
$$

Equivalently the canonical form may be given as

$$
M S E(\widetilde{\alpha})=\sigma^{2} \Delta \Lambda^{-1} \Delta+(I-\Delta)(\alpha-a)(\alpha-a)^{\prime}(I-\Delta) .
$$


Now we compare Shrinkage estimators and the LS estimator with respect to MSE matrix in equation (2.4). A Shrinkage estimator $\widetilde{\beta}$ is at least as good as the LS estimator $\widehat{\beta}$, if the matrix difference $M S E(\widehat{\beta})-M S E(\widetilde{\beta})$ is n.n.d.. That is $M S E(\widehat{\beta})-M S E(\widetilde{\beta}) \geq 0$. It follows that the difference $M S E(\widehat{\beta})-M S E(\widetilde{\beta})$ is n.n.d. if and only if the inequality

$$
(\beta-b)^{\prime}(I+A)^{-1} X^{\prime} X(I-A)(\beta-b) / \sigma^{2} \leq 1
$$

is satisfied. If we use the canonical representation equation $(2.12)$, the condition equation (2.15) can be written as

$$
(\alpha-a)^{\prime}(I+\Delta)^{-1} \Lambda(I-\Delta)(\alpha-a) / \sigma^{2} \leq 1 .
$$

The inequality equation (2.16) can be stated as

$$
\sum_{i=1}^{q} \gamma_{i} \lambda_{i}\left(\alpha_{i}-a_{i}\right)^{2} / \sigma^{2} \leq 1
$$

Here, $\gamma_{i}=\frac{\left(1-\delta_{i}\right)}{\left(1+\delta_{i}\right)}[3]$.

The Ridge and Liu estimators, which are known to be Shrinkage estimators, can be defined respectively by,

$$
\begin{gathered}
\widetilde{\beta}_{R}=\left(X^{\prime} X+k I\right)^{-1} X^{\prime} Y \\
\widetilde{\beta}_{L i u}=\left(X^{\prime} X+I\right)^{-1}\left(X^{\prime} Y+d \widehat{\beta}\right)
\end{gathered}
$$

where $0<\mathrm{k}<1$ and $0<\mathrm{d}<1[4]$. Substituting $\Delta=(\Lambda+k I)^{-1} \Lambda$ in equation (2.16), the inequalities,

$$
\begin{gathered}
\frac{(\beta-b)^{\prime}\left(\frac{2}{k} I+\left(X^{\prime} X\right)^{-1}\right)^{-1}(\beta-b)}{\sigma^{2}} \leq 1 \\
\frac{(\alpha-a)^{\prime}\left(\frac{2}{k} I+\Lambda^{-1}\right)^{-1}(\alpha-a)}{\sigma^{2}} \leq 1
\end{gathered}
$$

which are necessary and sufficient conditions for the Ridge estimator and at least as good as the LS estimator can be written [2]. In a similar way, substituting $\Delta=(\Lambda+I)^{-1}(\Lambda+d I)$ in equation (2.16), the inequalities,

$$
\frac{(\beta-b)^{\prime}\left(X^{\prime} X+2 I+d\left(X^{\prime} X\right)^{-1}\right)^{-1}\left(\left(X^{\prime} X\right)^{2}+d I\right)(\beta-b)}{\sigma^{2}} \leq 1
$$


or

$$
\frac{(\alpha-a)^{\prime}\left(\Lambda+2 I+d \Lambda^{-1}\right)^{-1}\left(\Lambda^{2}+d I\right)(\alpha-a)}{\sigma^{2}} \leq 1
$$

which are necessary and sufficient conditions for the Liu estimator and at least as good as the LS estimator can be written [7].

2.1. A Test for Choosing a Shrinkage Estimator. Using the necessary and sufficient conditions given in equation (2.15) and equation (2.16) it is possible to make a choose between two the estimators. In this case, the test statistic to be used for making a chose between the Shrinkage estimator $\widetilde{\beta}$ and the LS estimator $\widehat{\beta}$ is based on the given inequalities that inequality. Liski (1982) investigated the test statistic

$$
\widetilde{F}=\frac{\widehat{\beta}^{\prime} H \widehat{\beta}}{m \widehat{\sigma}^{2}}
$$

where $\mathrm{H}=(I+A)^{-1} X^{\prime} X(I-A), \widehat{\sigma}^{2}=\frac{(Y-X \widehat{\beta})^{\prime}(Y-X \widehat{\beta})}{(n-q)}, \operatorname{rank}(H)=m$ and $b=0[2]$. The canonical form of this statistic can be written as

$$
\widetilde{F}=\frac{\widehat{\alpha}^{\prime}(I+\Delta)^{-1} \Lambda(I-\Delta) \widehat{\alpha}}{m \sigma^{2}}=\frac{1}{m} \sum_{i=1}^{q} \gamma_{i}\left(\lambda_{i} \widehat{\alpha}_{i}^{2} / \widehat{\sigma}^{2}\right) .
$$

Here $m=\operatorname{rank}(I+\Delta)^{-1} \Lambda(I-\Delta)$. We may write

$$
\widetilde{F}=\frac{1}{m} \sum_{i=1}^{m} \gamma_{i}\left(\lambda_{i} \widehat{\alpha}_{i}^{2} / \widehat{\sigma}^{2}\right)
$$

The $m$ 's are the number of non-zero $\gamma_{i}$ 's. As it could be seen, $m$ satisfies $1 \leq m \leq q$. When we write

$$
F_{i}=\frac{\lambda_{i} \widehat{\alpha}_{i}^{2}}{\widehat{\sigma}^{2}}
$$

we can obtain

$$
\widetilde{F}=\frac{1}{m} \sum_{i=1}^{m} \gamma_{i} F_{i}
$$

$F_{i}=\frac{\lambda_{i} \widehat{\alpha}_{i}^{2}}{\widehat{\sigma}^{2}}$ fits an $F$ distribution with the non-central parameter $w_{i}=\frac{\lambda_{i} \alpha_{i}^{2}}{\sigma^{2}}$ and degrees of freedom 1 and $(n-q)[3],[7],[12]$. 
The necessary and sufficient conditions for the Shrinkage estimator mentioned above is $\sum_{i=1}^{m} \gamma_{i} w_{i} \leq 1$. Thus, hypothesis test can be written as

$$
\begin{aligned}
& H_{0}: \sum_{i=1}^{m} \gamma_{i} w_{i} \leq 1 \\
& H_{1}: \sum_{i=1}^{m} \gamma_{i} w_{i}>1 .
\end{aligned}
$$

The proposed test procedure is given by the decision rules:

If $\widetilde{F} \leq \widetilde{F}_{\alpha}(m, n-q, 1)$ then accept $H o$,

and

If $\widetilde{F}>\widetilde{F}_{\alpha}(m, n-q, 1)$ then reject $H o$.

Here $\widetilde{F}_{\alpha}(m, n-q, 1)$, is formed from the distribution $\widetilde{F}$, which has a non-central parameter $w=\sum_{i=1}^{m} \gamma_{i} w_{i}=1$ and degrees of freedom $m$ and $(n-q)$. Using the central-F approximation for $\widetilde{F}$ described below, the values of $\widetilde{F}_{\alpha}(m, n-q, 1)$ at the critical points are determined. Then the initial moments for the test statistic $\widetilde{F}$ are obtained from the moments of the statistic $F_{i}$ by using the method of moments. The first two central moments of the test statistic $\widetilde{F}$ are [9]

$$
\begin{aligned}
& E \widetilde{F}=\frac{(n-q)}{(n-q-2) m}\left[\sum_{i=1}^{m} \gamma_{i}\left(1+w_{i}\right)\right], \quad((n-q)>2) \\
& E \widetilde{F}^{2}=\frac{(n-q)^{2}}{(n-q-2)(n-q-4) m^{2}}\left\{\begin{array}{c}
{\left[\sum_{i=1}^{m} \gamma_{i}\left(1+w_{i}\right)\right]^{2}} \\
+2 \sum_{i=1}^{m} \gamma_{i}^{2}\left(1+2 w_{i}\right)
\end{array}\right\},((n-q)>4) .
\end{aligned}
$$

2.2. Central-F Approach for $\widetilde{F}$ Statistics: Patnaik (1949) studied a central- $F$ approximation to the non-central $F$ distribution [13]. He used the first two moments of the central- $F$ distribution $F(\vartheta, n-q)$ and the non-central $F$ distribution $\widetilde{F}(m, n-q, w)$, and obtained that

$\widetilde{F}(m, n-q, w) \approx r F(\vartheta, n-q)$.

The parameters $r$ and $\vartheta$ are found from the first two moments of the distribution $F$. In other words, the two moments approximation of central- $F$ can be performed by equating the first two moments of central- $F$ and $\widetilde{F} / r$.

By solving these equations

$$
r=\frac{1}{m} \sum_{i=1}^{m} \gamma_{i}\left(1+w_{i}\right)
$$




$$
\begin{gathered}
\text { and } \\
\vartheta=\frac{\left[\sum_{i=1}^{m} \gamma_{i}\left(1+w_{i}\right)\right]^{2}}{\sum_{i=1}^{m} \gamma_{i}^{2}\left(1+2 w_{i}\right)}
\end{gathered}
$$

could be written. When $\gamma=\sum_{i=1}^{q} \gamma_{i}$ and $\sum_{i=1}^{m} \gamma_{i} w_{i}=1$ are given, the scale factor $r$ can be determined from $r=\frac{\gamma+1}{m}$. The values of $\gamma_{i}$ lie in the interval $[0,1]$, and the degrees of freedom can be written as

$$
\vartheta=\frac{(\gamma+1)^{2}}{\left(\sum_{i=1}^{m} \gamma_{i}^{2}+2 \sum_{i=1}^{m} \gamma_{i}^{2} w_{i}\right)}
$$

From this, it could be seen that [8].

$$
\gamma_{\min } \leq \sum_{i=1}^{m} \gamma_{i}^{2} w_{i} \leq \gamma_{\max }
$$

From equation (2.30), the upper and lower limits of the degrees of freedom $\vartheta$ are found to be:

$$
(\gamma+1)^{2} /\left(\sum_{i=1}^{m} \gamma_{i}^{2}+2 \gamma_{\max }\right) \leq \vartheta \leq(\gamma+1)^{2} /\left(\sum_{i=1}^{m} \gamma_{i}^{2}+2 \gamma_{\min }\right) .
$$

The upper limit is denoted by $\vartheta_{\max }$, and the lower limit by $\vartheta_{\min }$. Hence, for all $0<\alpha<1$ we have $F_{\alpha}\left(\vartheta_{\max }, n-q\right) \leq F_{\alpha}\left(\vartheta_{\min }, n-q\right)$, so we obtain the critical points $F_{\alpha}\left(\vartheta_{\max }, n-q\right)$ and $F_{\alpha}\left(\vartheta_{\min }, n-q\right)$. The statistic $\widetilde{F} / r$ is compared with these values. Hence, by using these critical points, the following regions for the test statistic can be obtained

Reject $H o$ if $\widetilde{F} / r>F_{\alpha}\left(\vartheta_{\min }, n-q\right)$,

Accept $H o$ if $\widetilde{F} / r<F_{\alpha}\left(\vartheta_{\max }, n-q\right)$,

Inconclusive if $F_{\alpha}\left(\vartheta_{\max }, n-q\right) \leq \widetilde{F} / r \leq F_{\alpha}\left(\vartheta_{\min }, n-q\right)$.

\section{A Simulation STUDY}

In this section we describe a simulation that was performed using a MATLAB package programme for comparing the Ridge and Liu estimators with the LS estimator. 
Firstly, the independent variables $X=\left(\begin{array}{ll}x_{1} & x_{2}\end{array}\right)$ are chosen from a normal distribution with parameters $\mu=(9,8), \sigma_{1}^{2}=9, \sigma_{2}^{2}=9$, correlation coefficients $\rho=0.1$, $0.5,0.9$ and sample sizes $n=30,60,100$ and 1000 . Then, the error vector $\varepsilon$ is chosen from a standard normal distribution and the dependent variable $Y$ is determined as follows

$Y=3.5+3 x_{1}+2.5 x_{2}+\varepsilon$.

In addition, for the Ridge and Liu estimators, $k=0.01(0.01) 0.99$ and $d=$ 0.01(0.01)0.99, respectively, were used and for each of these the values of $\widetilde{F}, \widetilde{F} / r$, $F_{\alpha}\left(\vartheta_{\min }, n-q\right)$ and $F_{\alpha}\left(\vartheta_{\max }, n-q\right)$ were calculated. Finally, the regions of rejection, acceptance and inconclusive were found. For the Ridge estimator these are shown in Figures 1-12, and for the Liu estimator in Figures 13-24. 


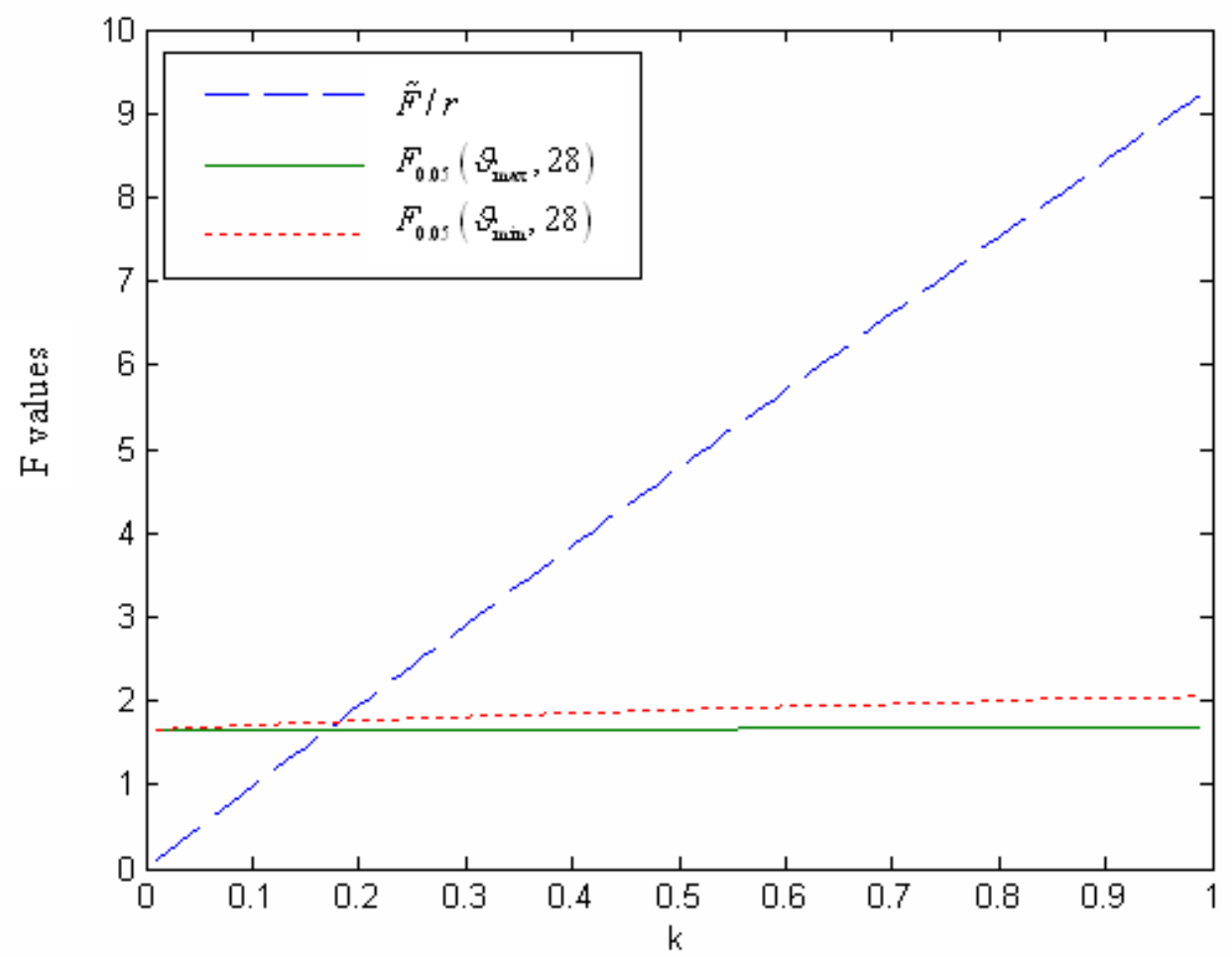

FIGURE 1: Rejected, accepted and inconclusive areas for Ridge estimators for $\rho=0.1$ and $n=30$

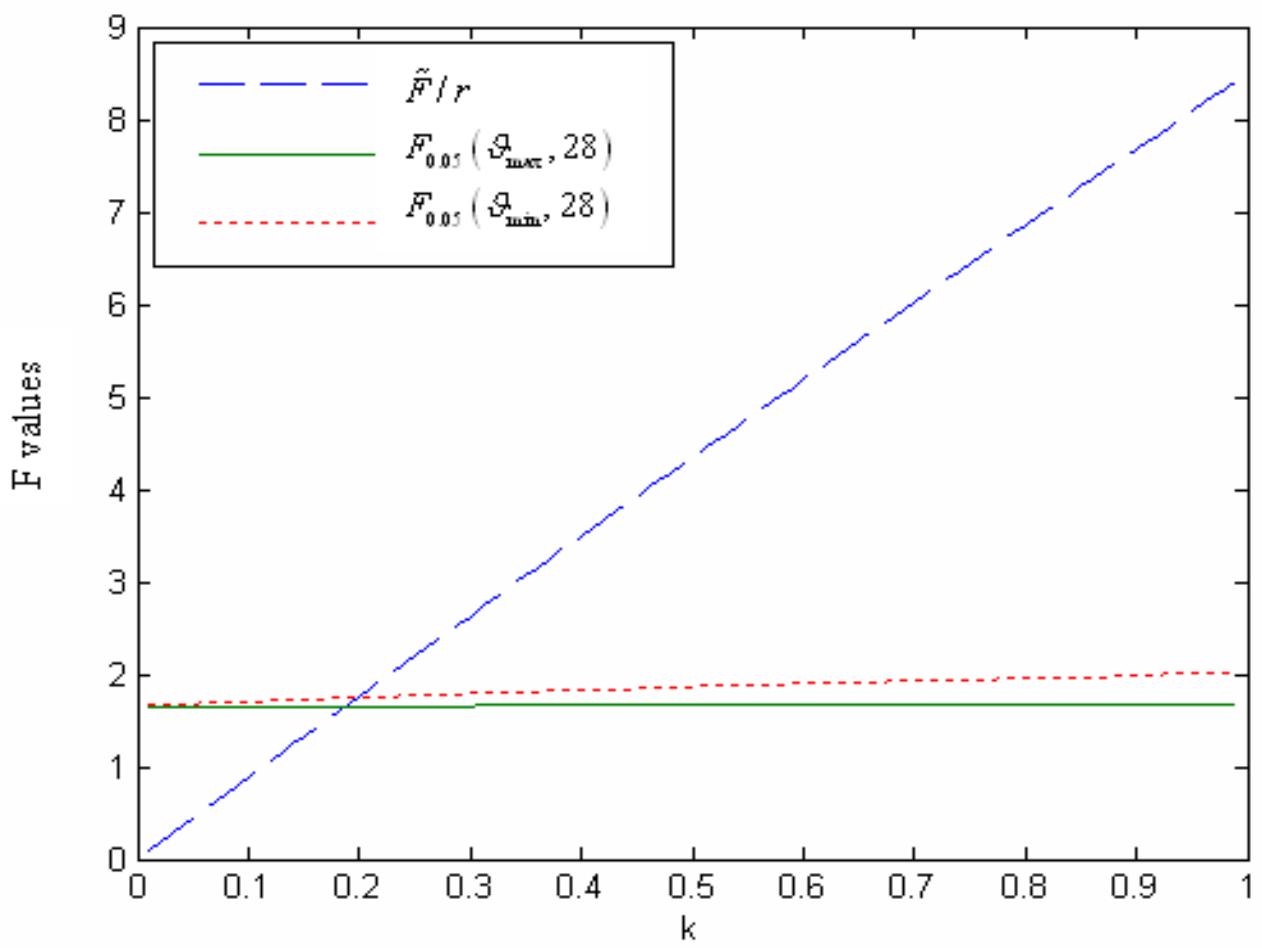

FIGURE 2: Rejected, accepted and inconclusive areas for Ridge estimators for $\rho=0.5$ and $n=30$ 


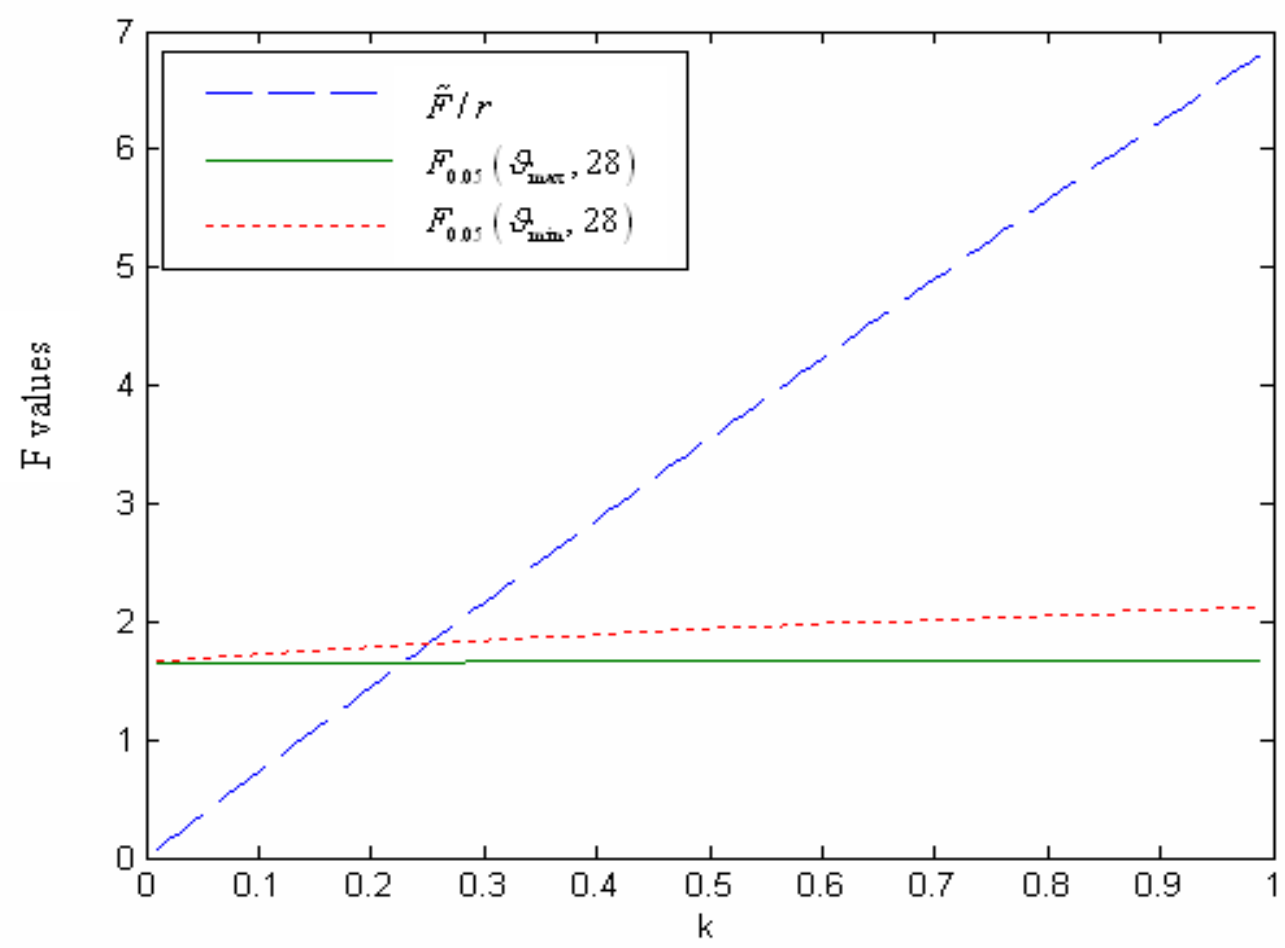

FIGURE 3: Rejected, accepted and inconclusive areas for Ridge estimators for $\rho=0.9$ and $n=30$

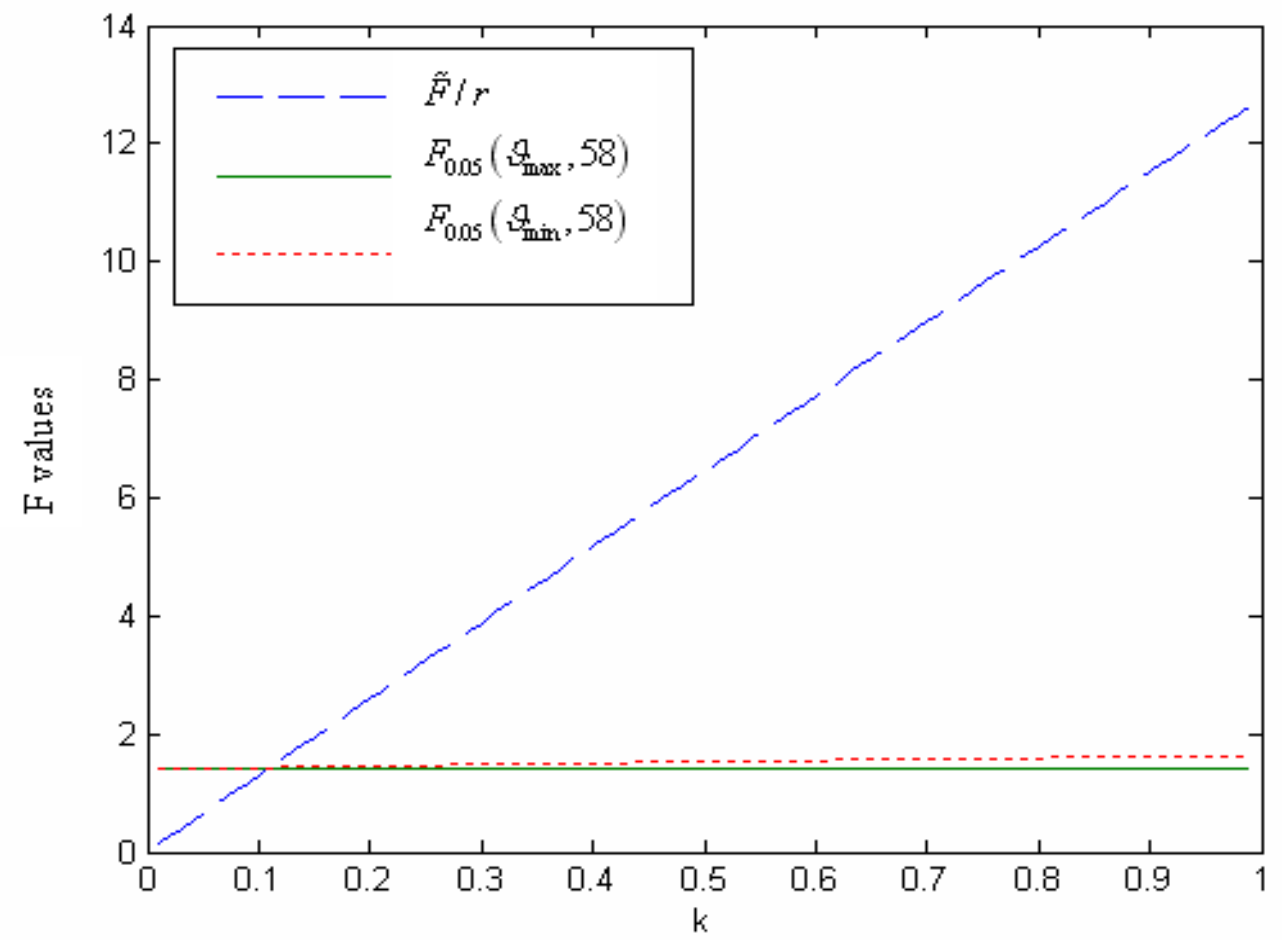

FIGURE 4: Rejected, accepted and inconclusive areas for Ridge estimators for $\rho=0.1$ and $n=60$ 


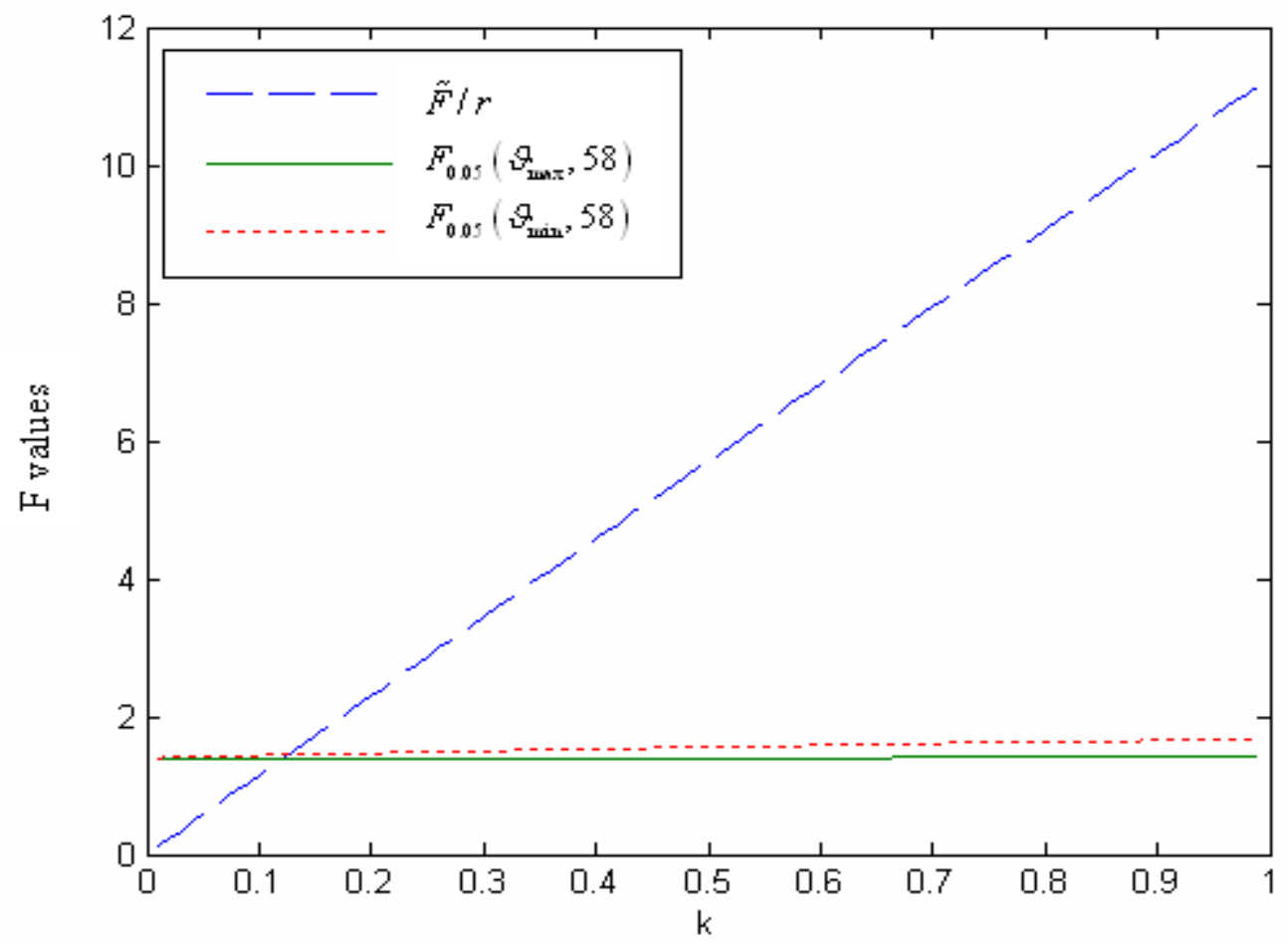

FIGURE 5: Rejected, accepted and inconclusive areas for Ridge estimators for $\rho=0.5$ and $n=60$

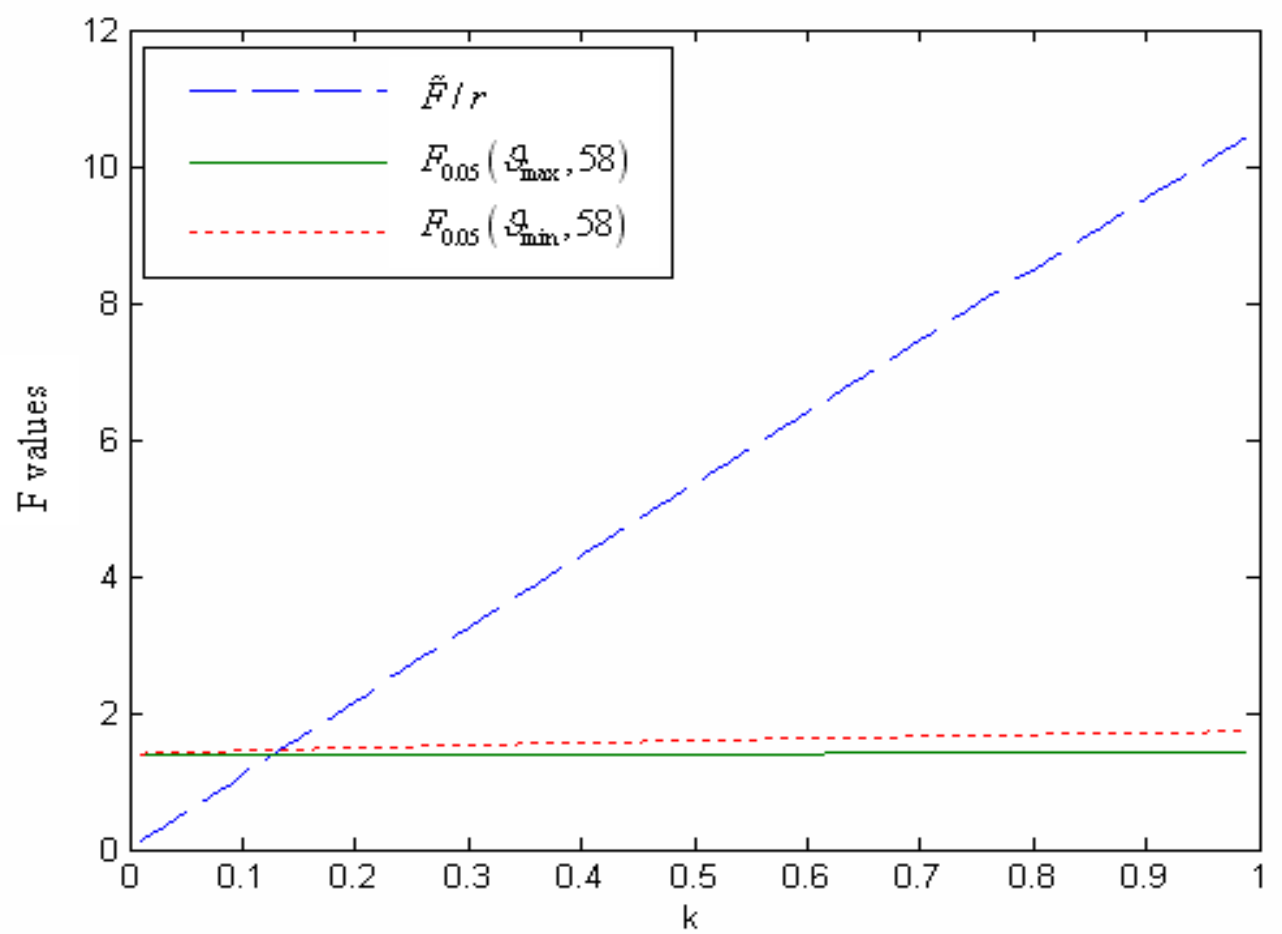

FIGURE 6: Rejected, accepted and inconclusive areas for Ridge estimators for $\rho=0.9$ and $n=60$ 


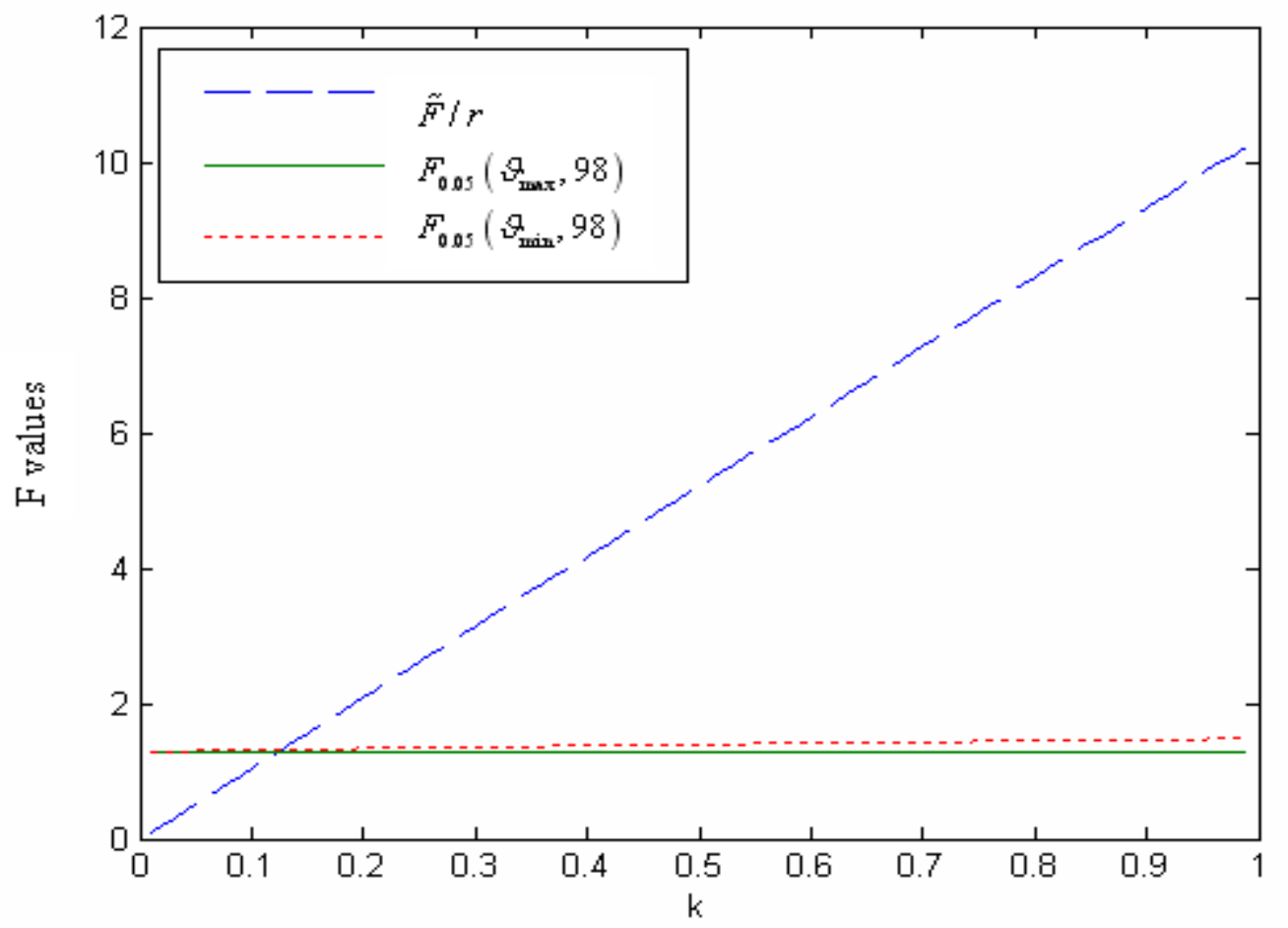

FIGURE 7: Rejected, accepted and inconclusive areas for Ridge estimators for $\rho=0.1$ and $n=100$

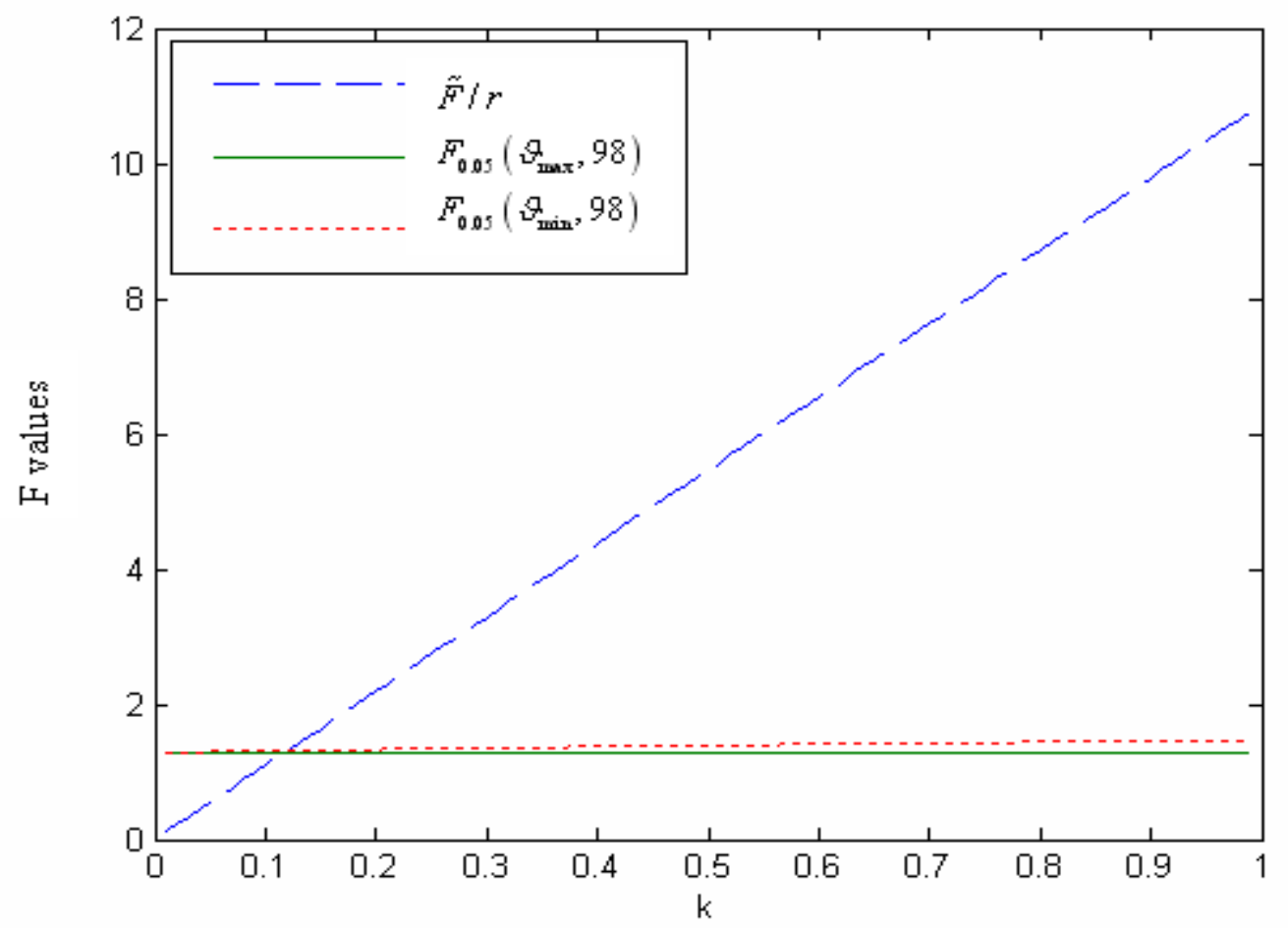

FIGURE 8: Rejected, accepted and inconclusive areas for Ridge estimators for $\rho=0.5$ and $n=100$ 


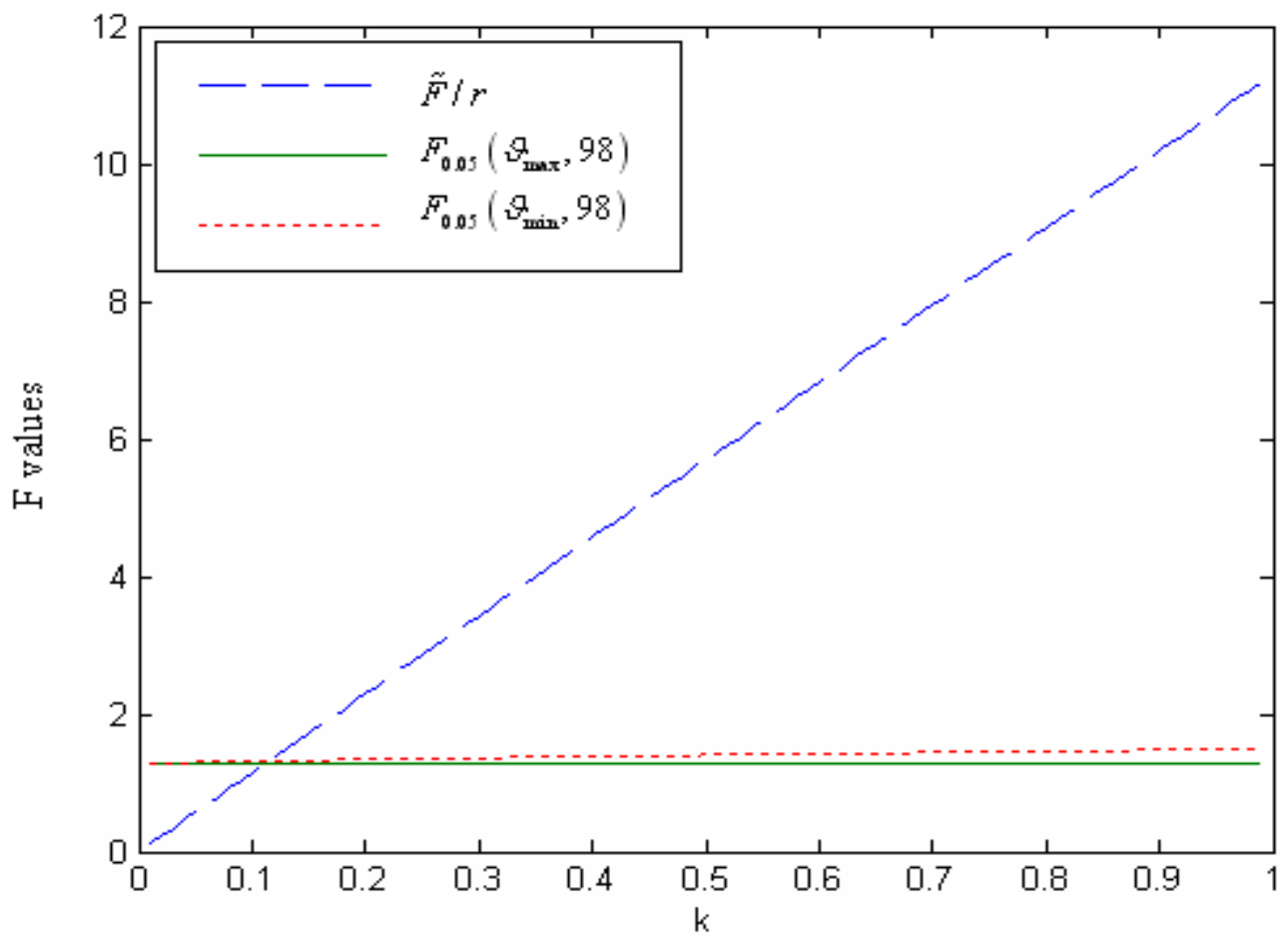

FIGURE 9: Rejected, accepted and inconclusive areas for Ridge estimators for $\rho=0.9$ and $n=100$

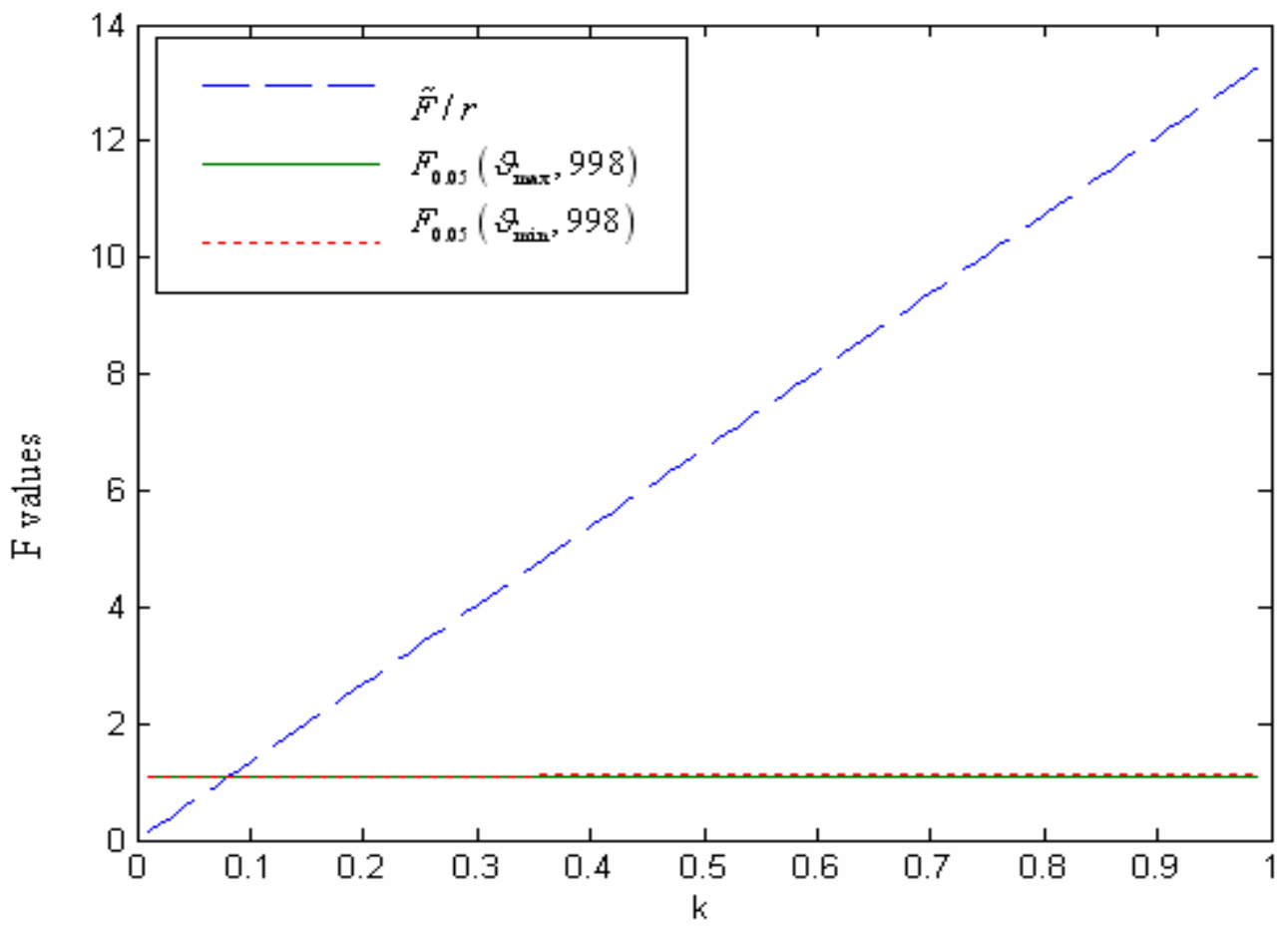

FIGURE 10: Rejected, accepted and inconclusive areas for Ridge estimators for $\rho=0.1$ and $n=1000$ 


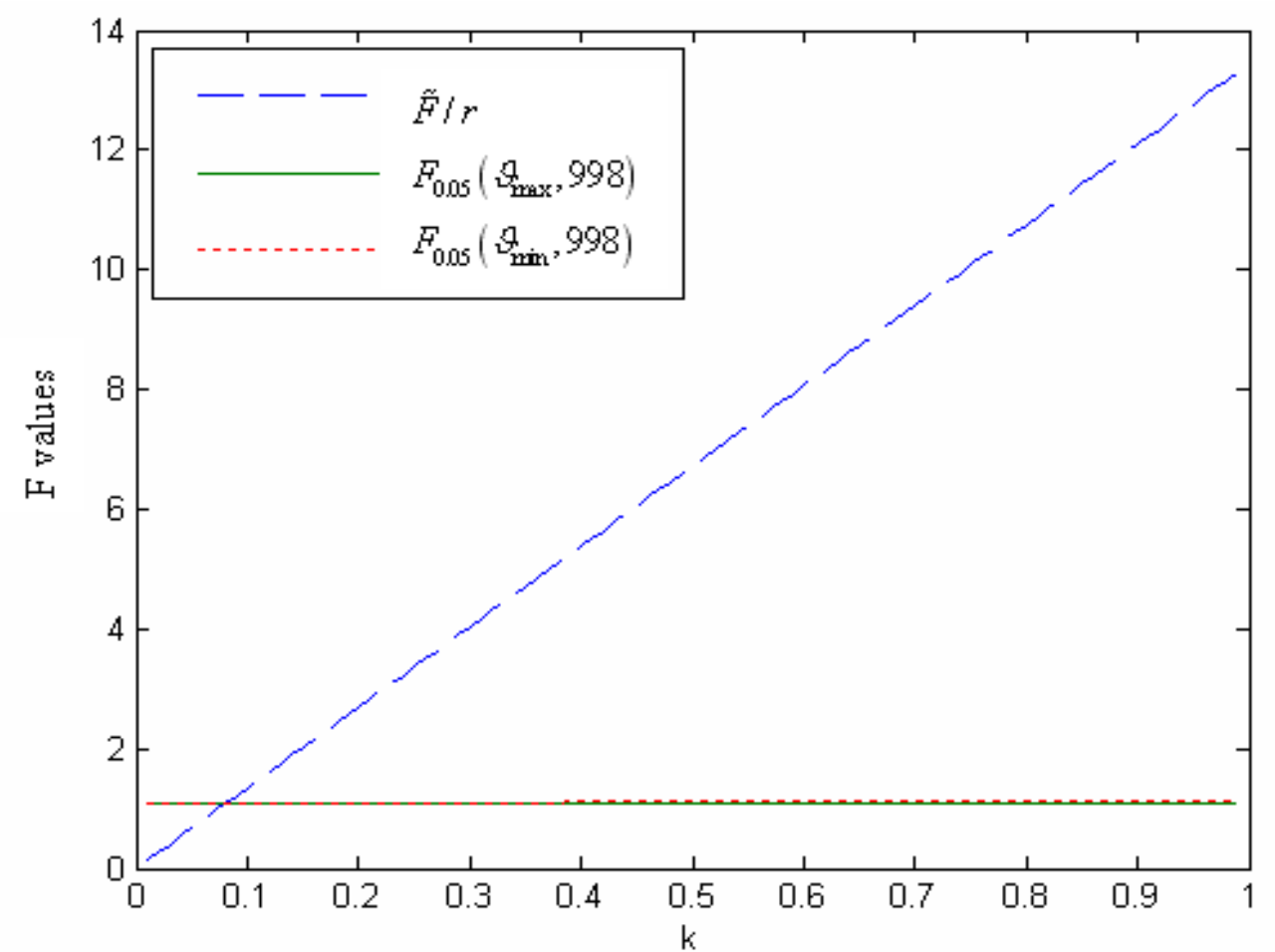

FIGURE 11: Rejected, accepted and inconclusive areas for Ridge estimators for $\rho=0.5$ and $n=1000$

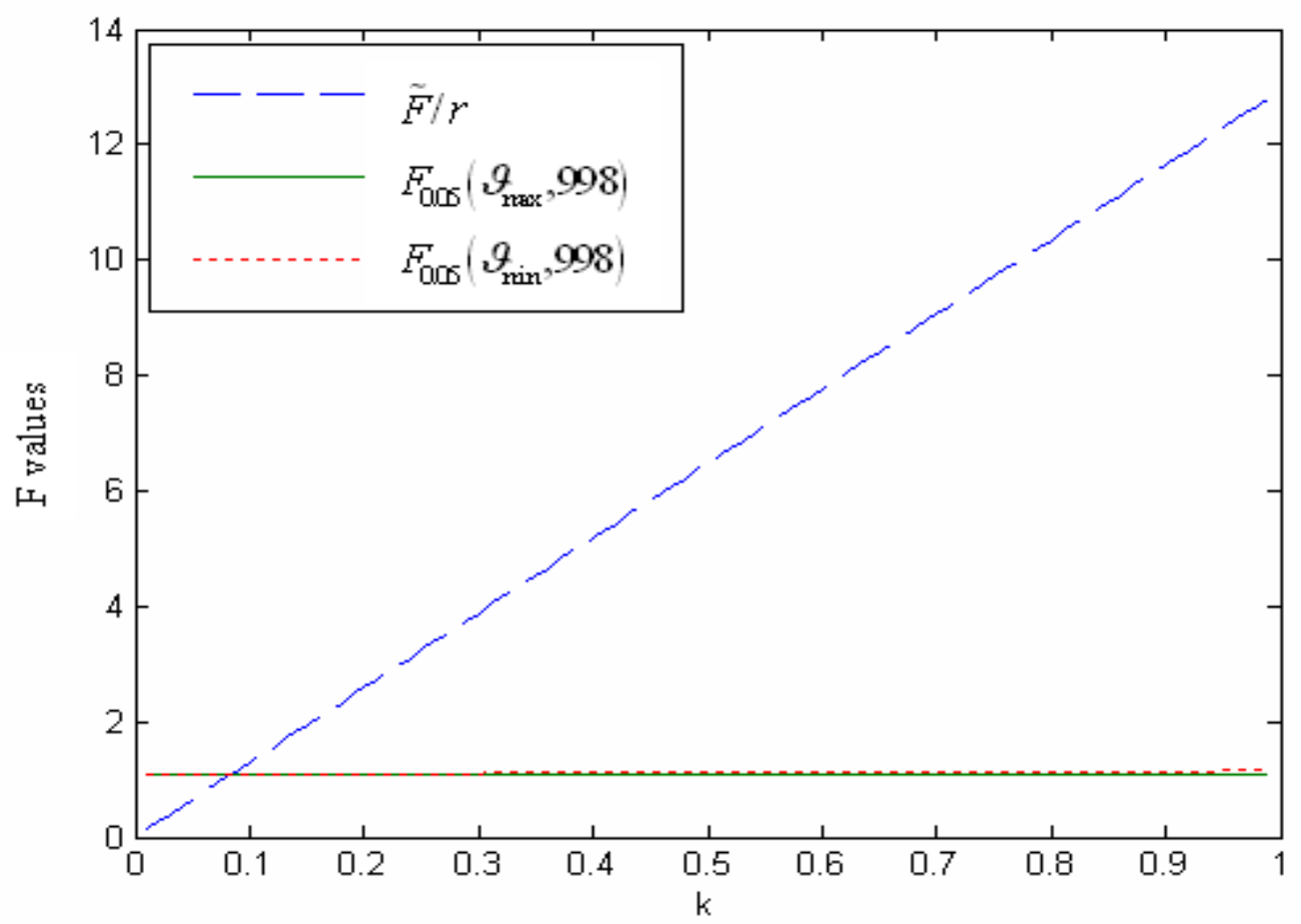

FIGURE 12: Rejected, accepted and inconclusive areas for Ridge estimators for $\rho=0.9$ and $n=1000$ 


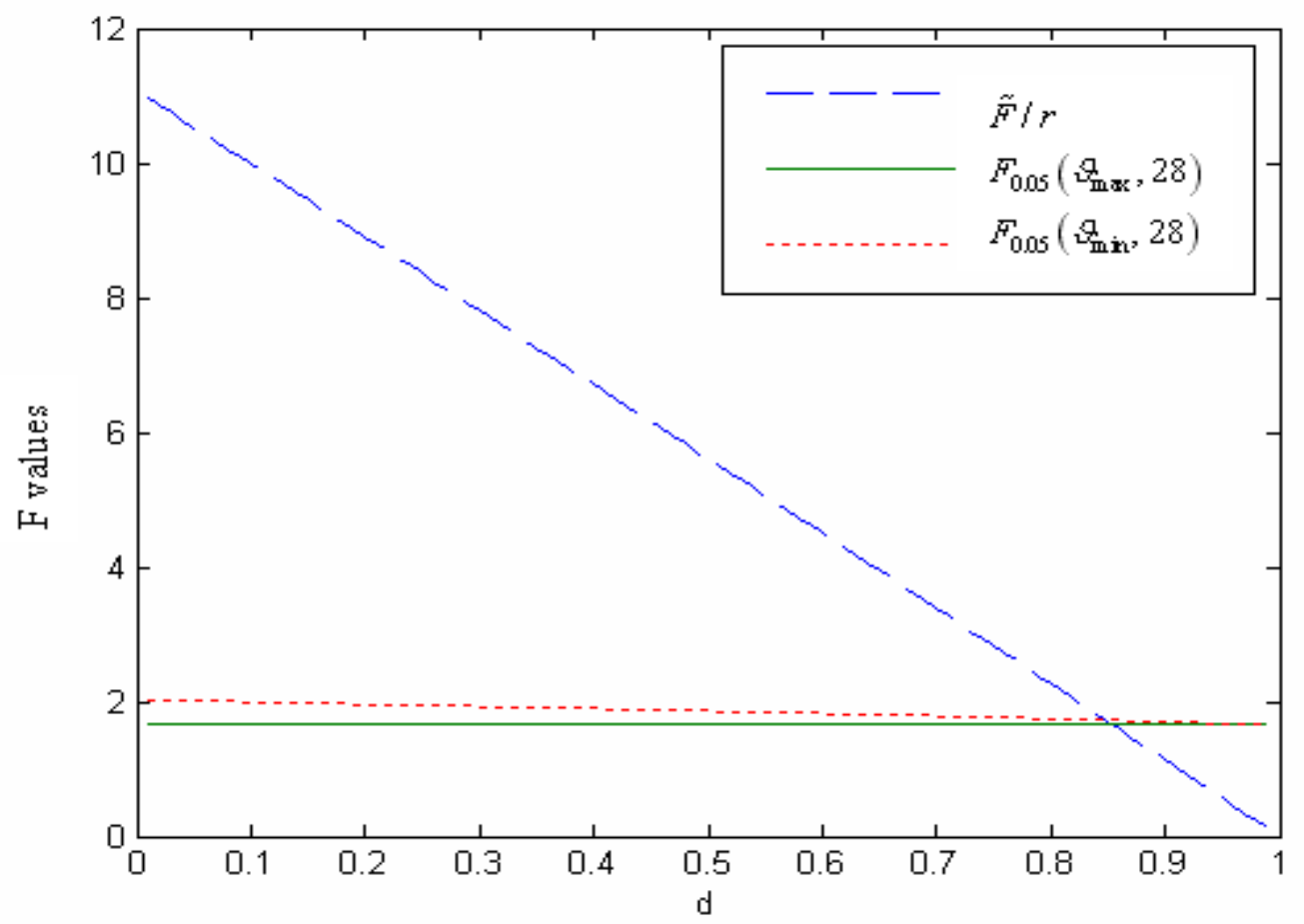

FIGURE 13: Rejected, accepted and inconclusive areas for Liu estimators for $\rho=0.1$ and $n=30$

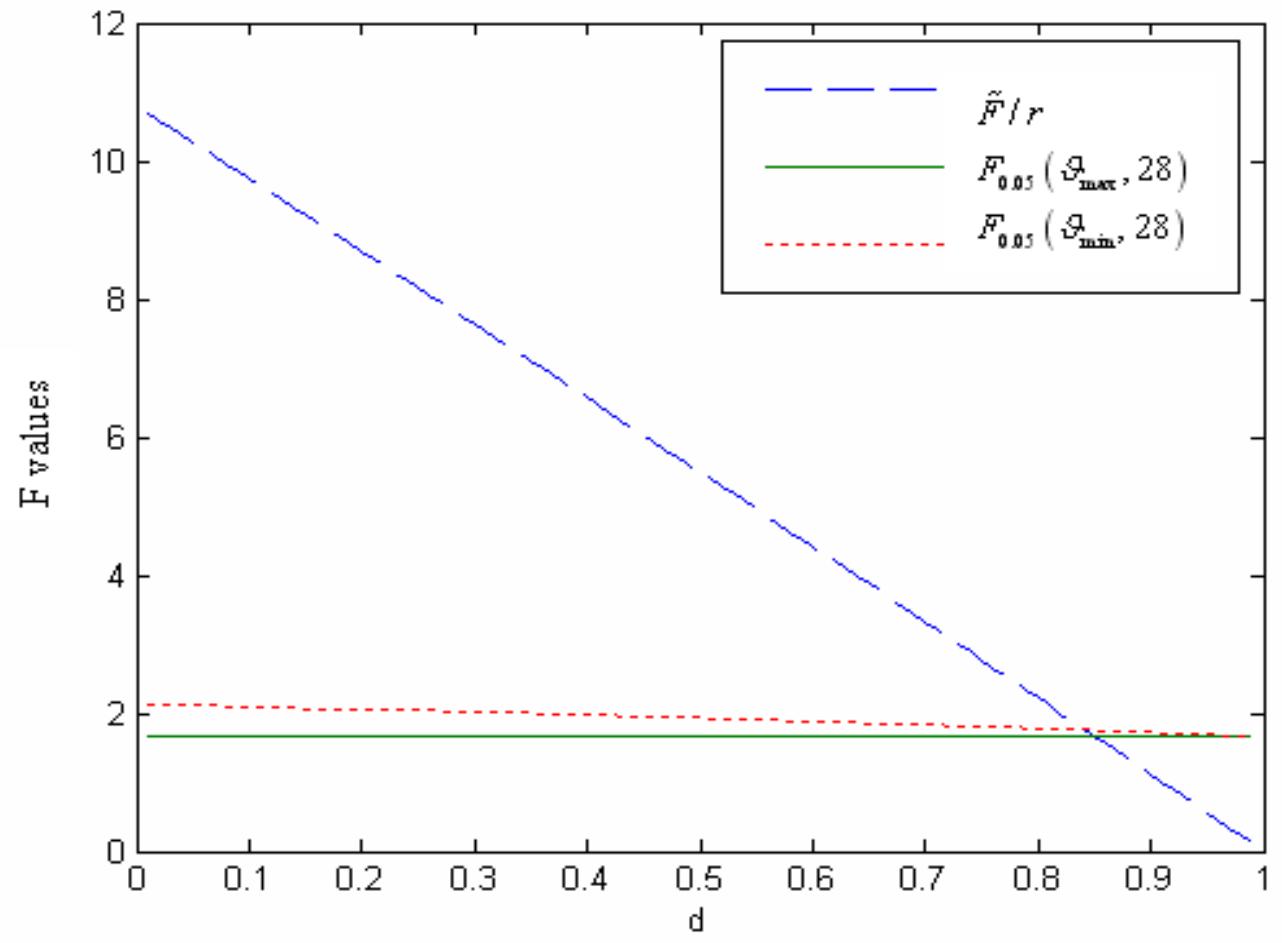

FIGURE 14: Rejected, accepted and inconclusive areas for Liu estimators for $\rho=0.5$ and $n=30$ 


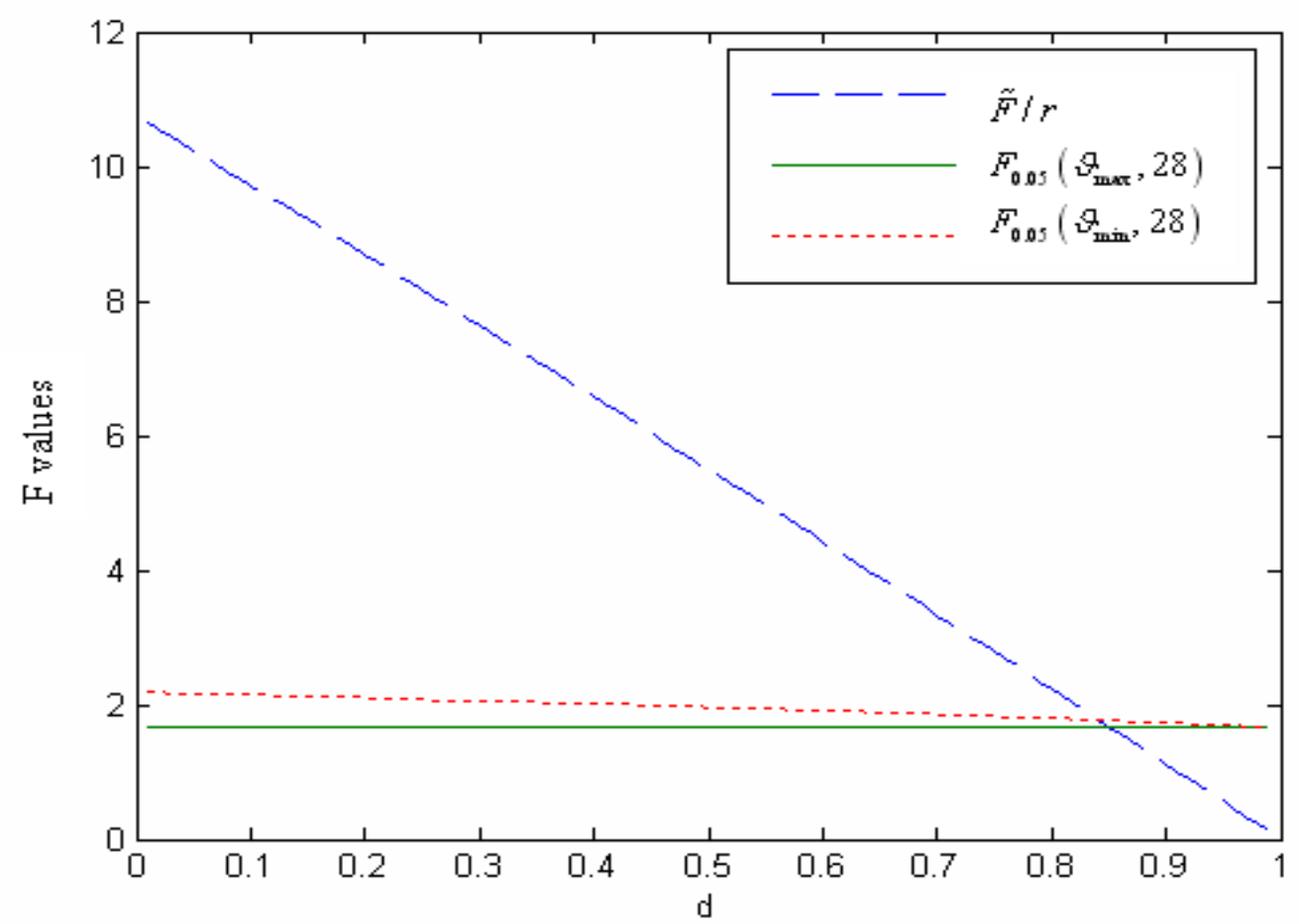

FIGURE 15: Rejected, accepted and inconclusive areas for Liu estimators for $\rho=0.9$ and $n=30$

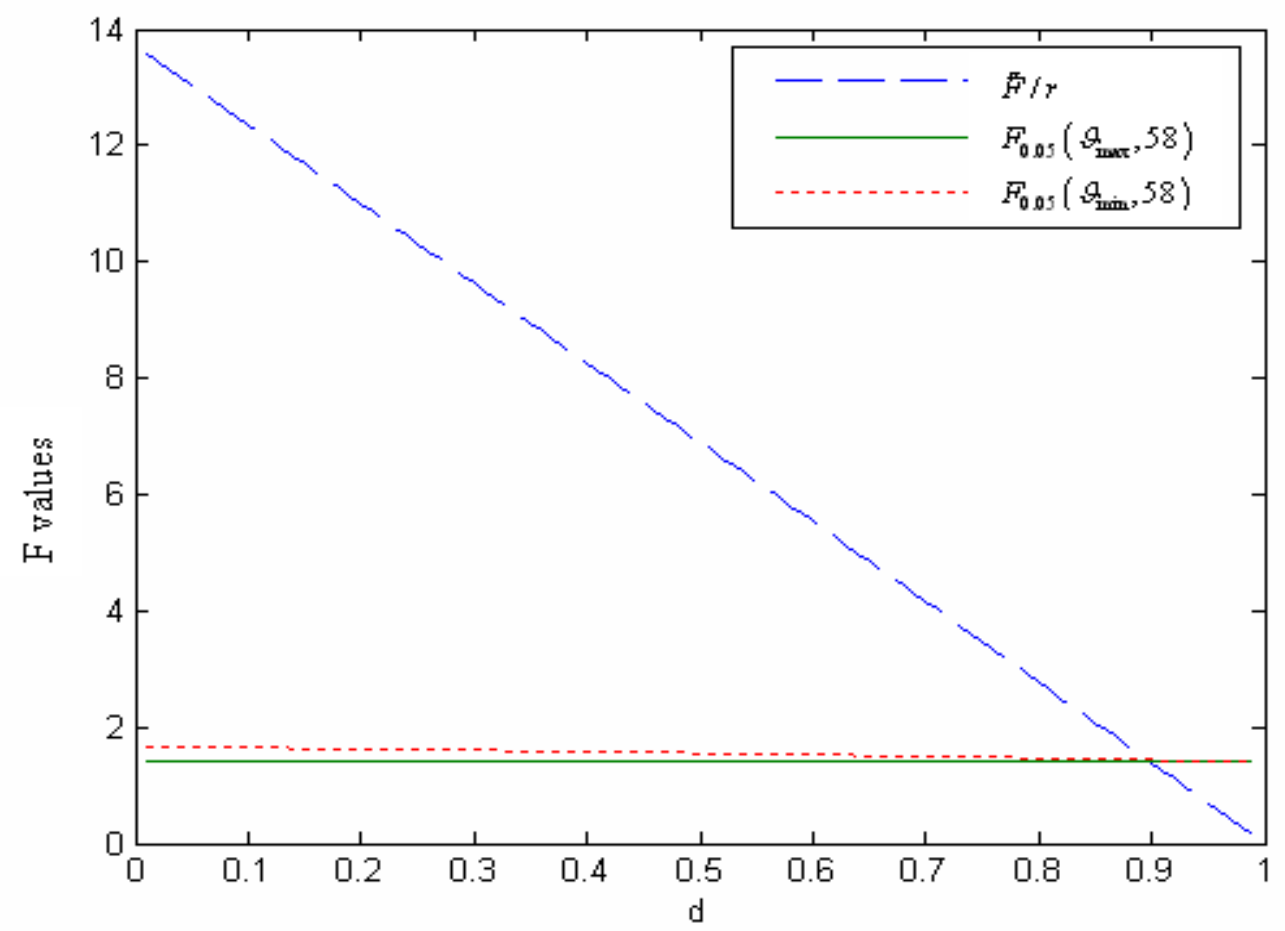

FIGURE 16: Rejected, accepted and inconclusive areas for Liu estimators for $\rho=0.1$ and $n=60$ 


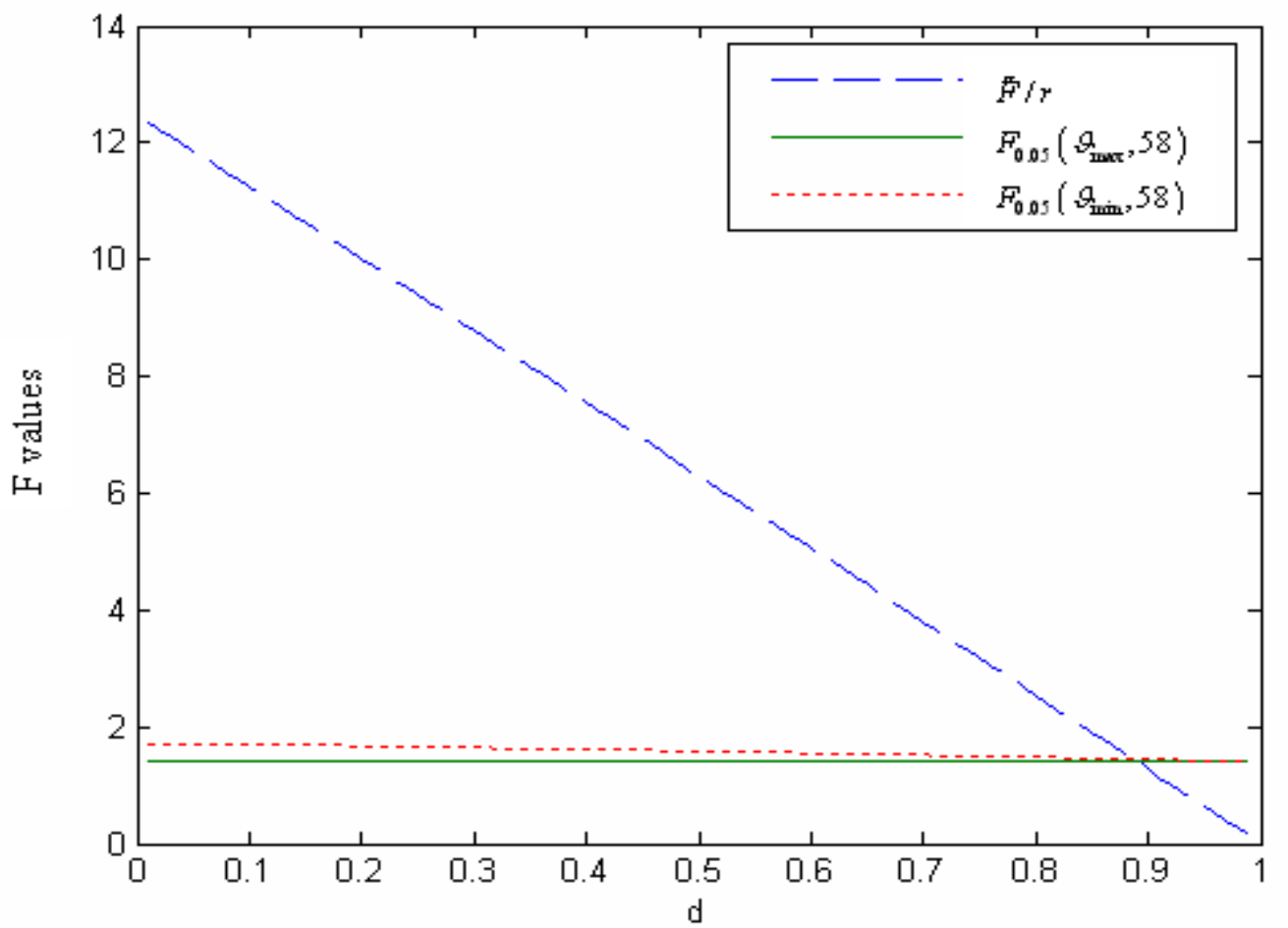

FIGURE 1ं: Rejected, accepted and inconclusive areas for Liu estimators for $\rho=0.5$ and $n=60$

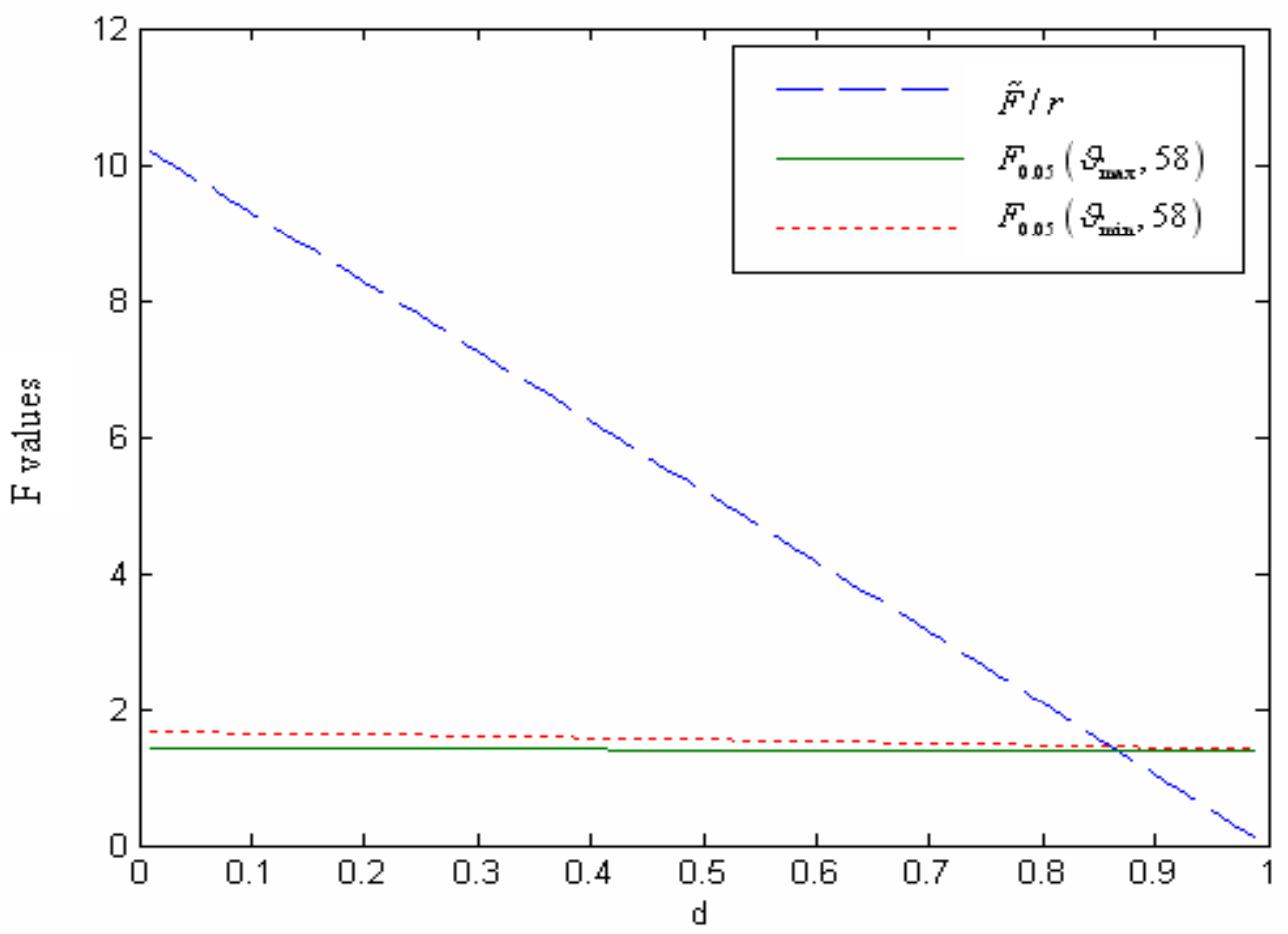

FIGURE 18: Rejected, accepted and inconclusive areas for Liu estimators for $\rho=0.9$ and $n=60$ 


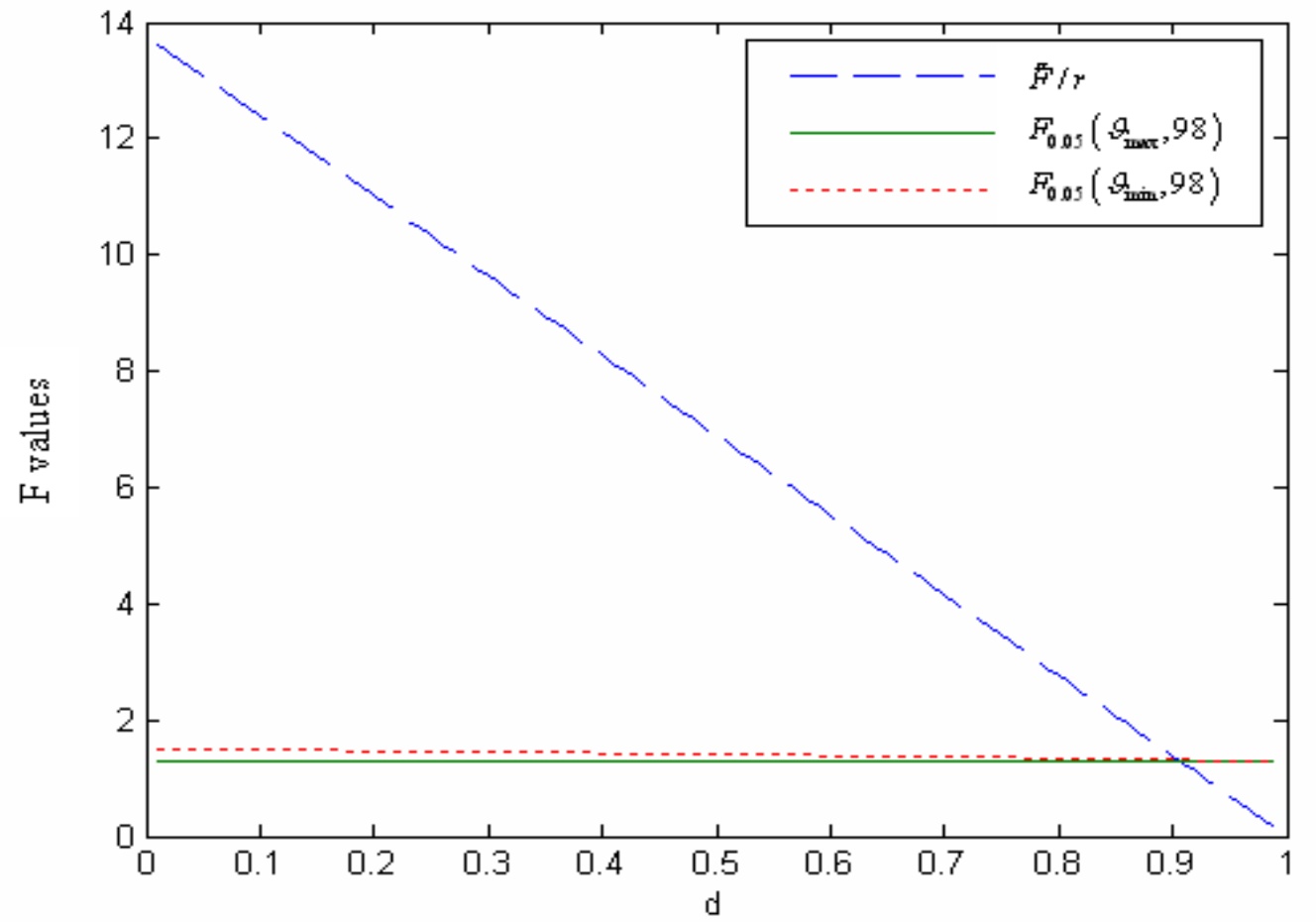

FIGURE 19: Rejected, accepted and inconclusive areas for Liu estimators for $\rho=0.1$ and $n=100$

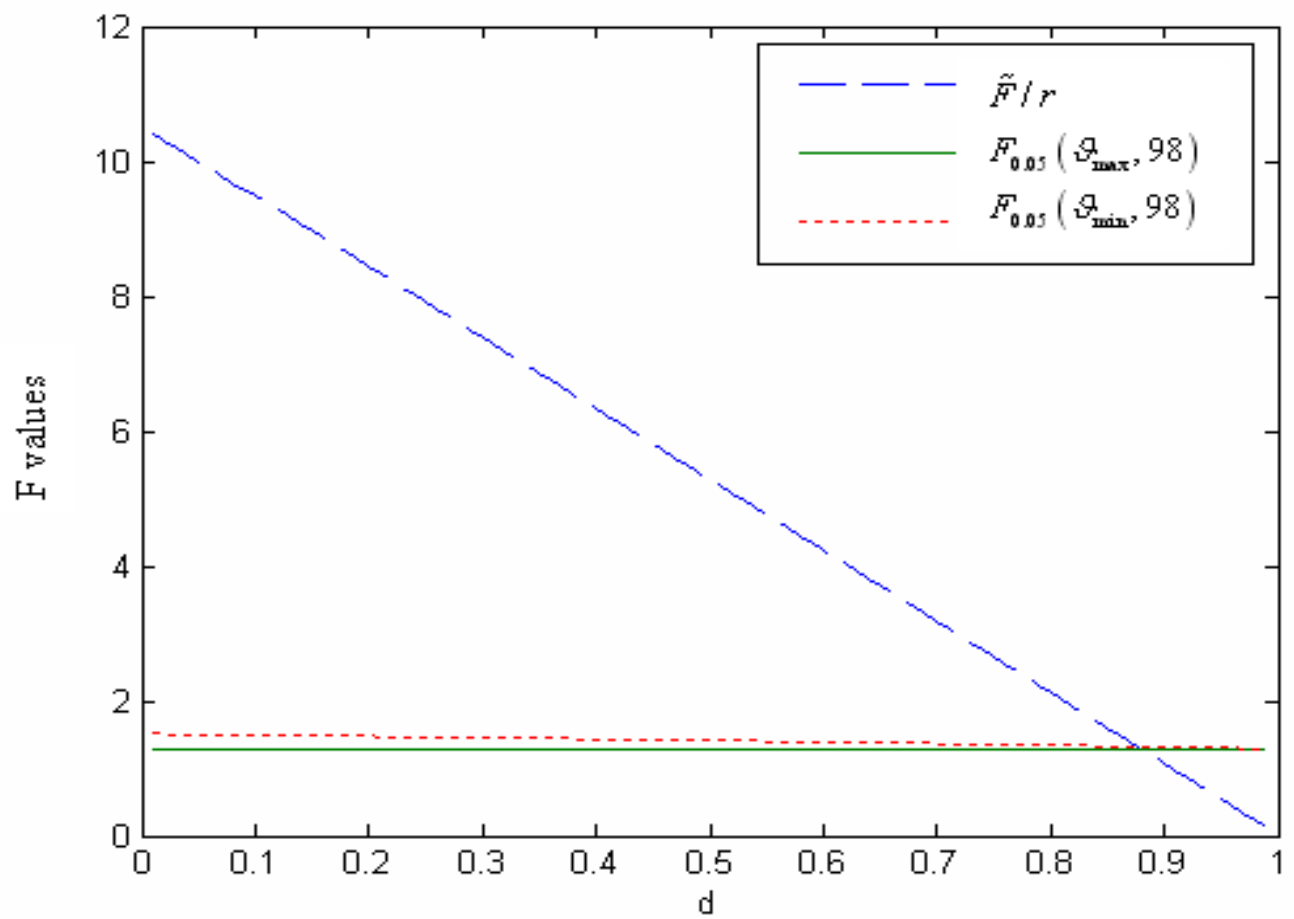

FIGURE 20: Rejected, accepted and inconclusive areas for Liu estimators for $\rho=0.5$ and $n=100$ 


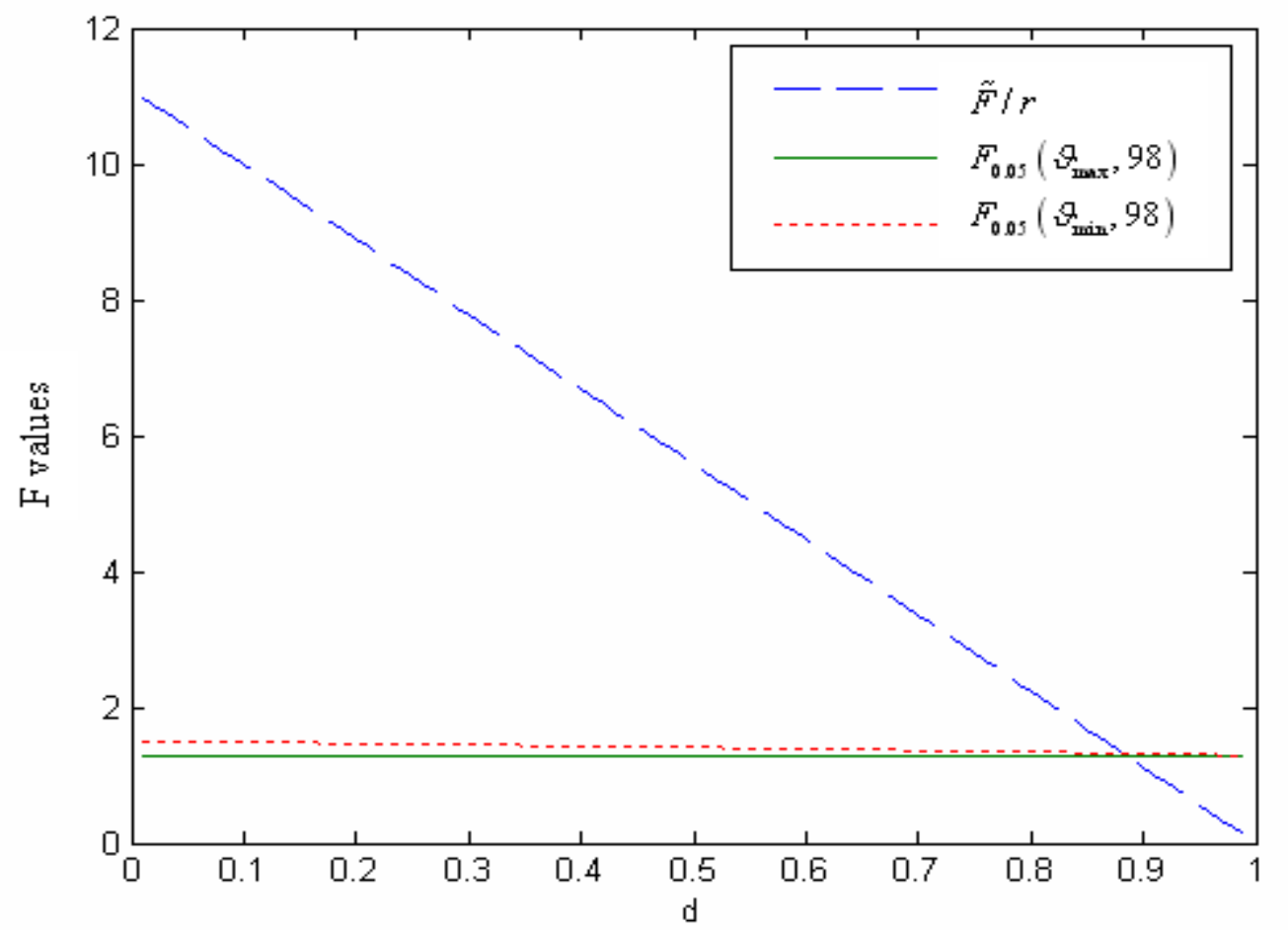

FIGURE 21: Rejected, accepted and inconclusive areas for Liu estimators for $\rho=0.9$ and $n=100$

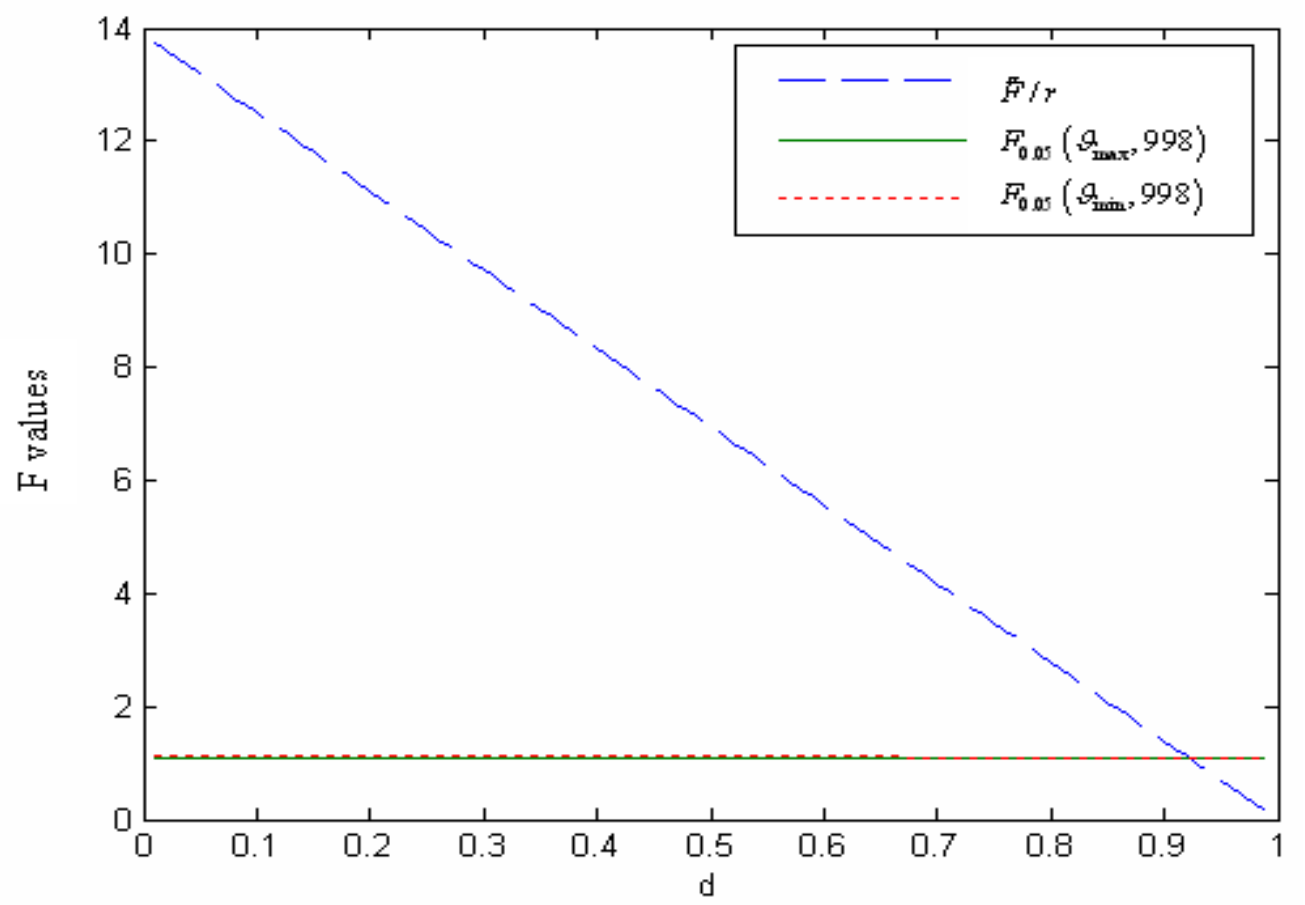

FIGURE 22: Rejected, accepted and inconclusive areas for Liu estimators for $\rho=0.1$ and $n=1000$ 


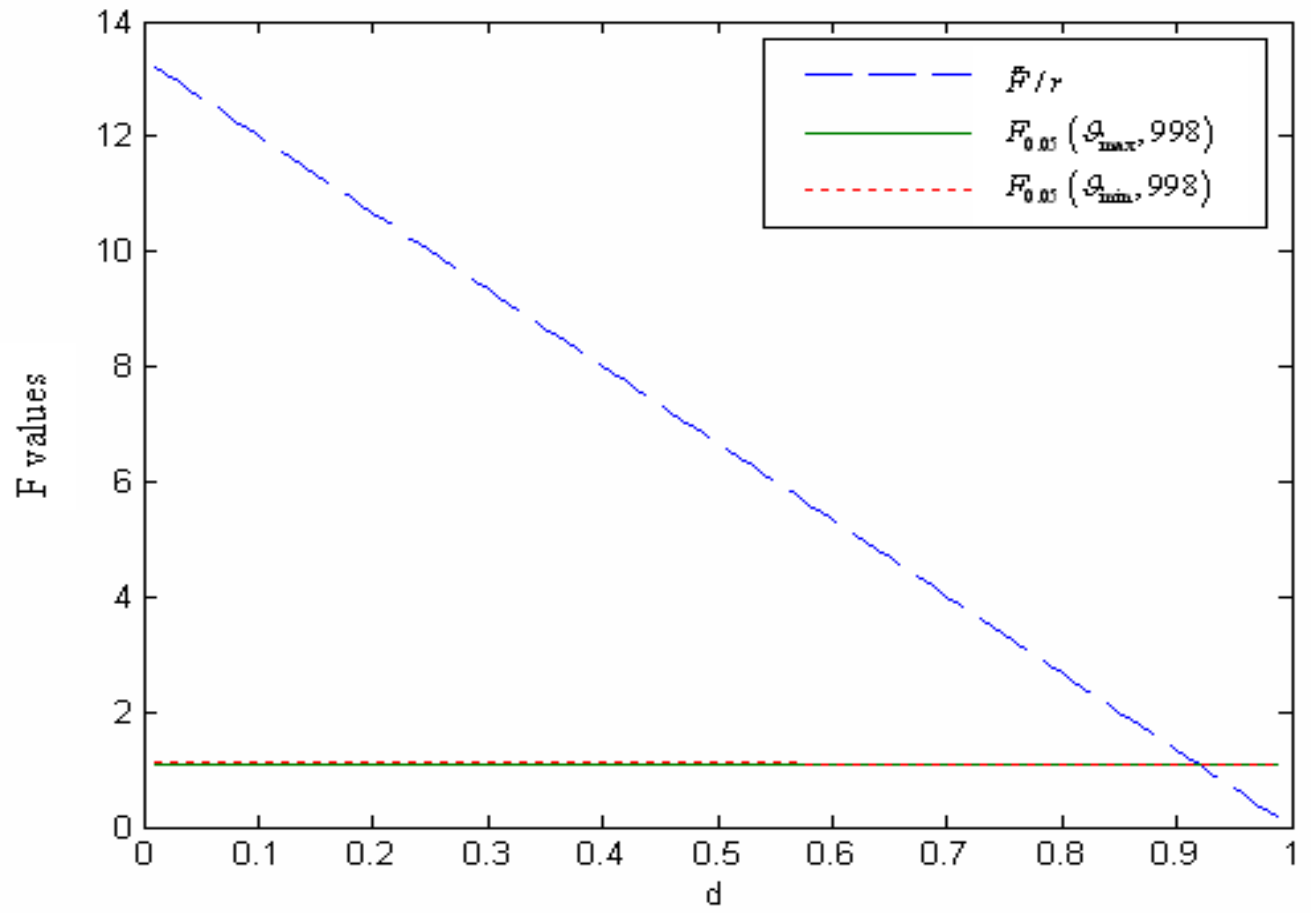

FIGURE 23: Rejected, accepted and inconclusive areas for Liu estimators for $\rho=0.5$ and $n=1000$

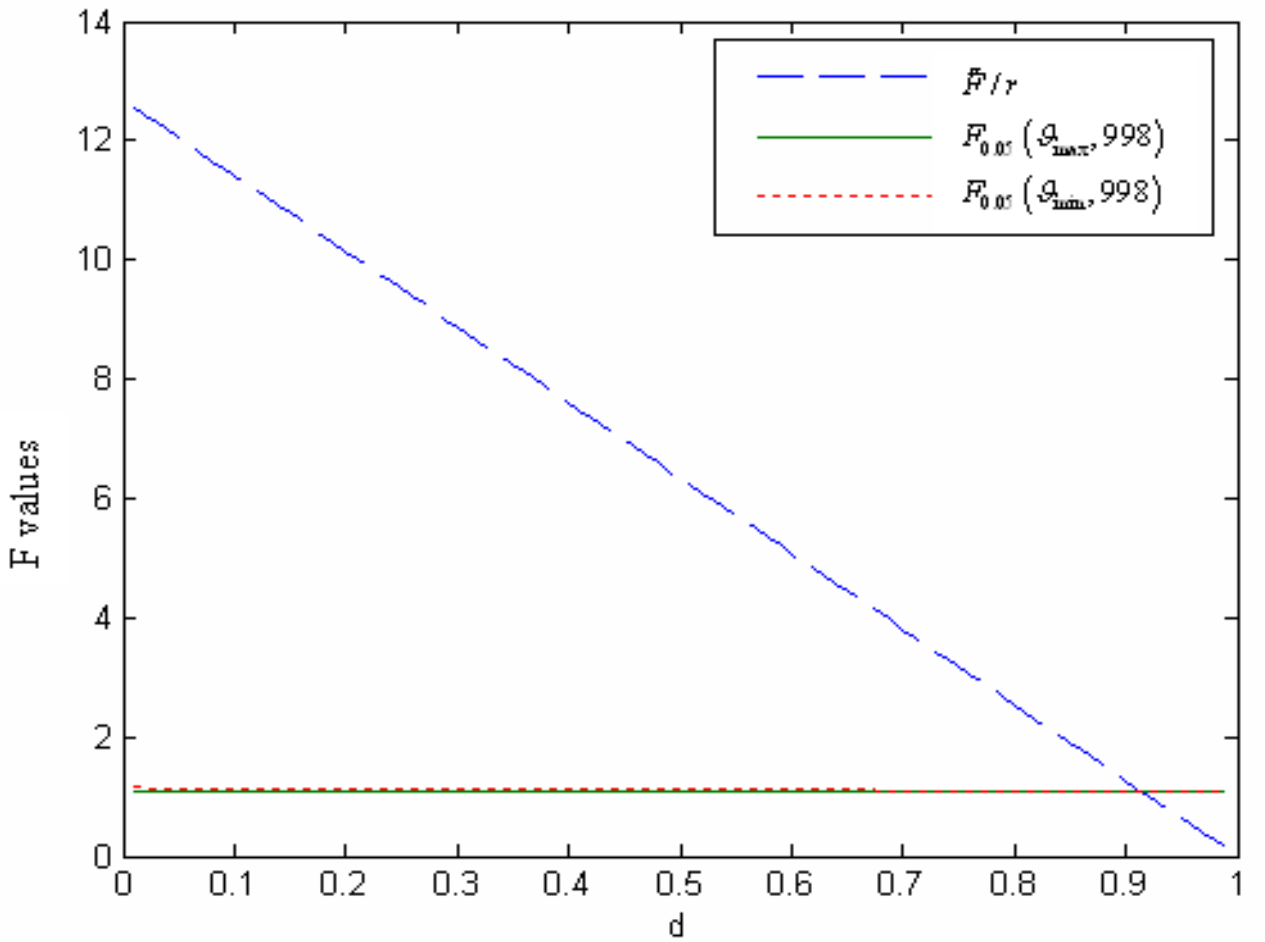

FIGURE 24: Rejected, accepted and inconclusive areas for Liu estimators for $\rho=0.9$ and $n=1000$ 


\section{THE SIMULATION STUDY RESULTS}

In this study, the Ridge and Liu estimators are examined for different sample sizes and correlation structures. Appropriate $k$ and $d$ value intervals satisfying that using Ridge and Liu estimators give better results than using LS estimator for sample sizes $n=30,60,100,1000$ and for correlation values of $\rho=0.1,0.5,0.9$ are obtained. These results for are given Figures 1-24

As seen from Figure 1, when $n=30$ and $\rho=0.1,0<k<0.18$ is a good value interval of $k$ for the Ridge estimator. For this interval, Ridge estimator gives better results than LS estimator. So, it is more appropriate to use the Ridge estimator instead of LS estimator. The Figures $1-12$, the $k$ value intervals, satisfying that Ridge estimator is more appropriate than LS estimators, are obtained and given in Table 1.

Similarly, when the Liu estimator is examined, it is seen that it gives similar results to the Ridge estimator. The Figures $13-24$, the $d$ value intervals, satisfying that Liu estimator is more appropriate than LS estimators, are obtained and given in Table 1.

Table 1: The value intervals of $k$ and $d$ for different sample sizes $(n)$ and correlation values $(\rho)$

\begin{tabular}{|r|c|c|c|c|c|}
\hline$n$ & $\rho$ & Figure No & Value interval of $k$ & Figure No & Value interval of $d$ \\
\hline 30 & 0.1 & 1 & $0<k<0.18$ & 13 & $0.87<d<1$ \\
\hline 30 & 0.5 & 2 & $0<k<0.20$ & 14 & $0.86<d<1$ \\
\hline 30 & 0.9 & 3 & $0<k<0.23$ & 15 & $0.84<d<1$ \\
\hline 60 & 0.1 & 4 & $0<k<0.10$ & 16 & $0.90<d<1$ \\
\hline 60 & 0.5 & 5 & $0<k<0.11$ & 17 & $0.89<d<1$ \\
\hline 60 & 0.9 & 6 & $0<k<0.12$ & 18 & $0.88<d<1$ \\
\hline 100 & 0.1 & 7 & $0<k<0.12$ & 19 & $0.90<d<1$ \\
\hline 100 & 0.5 & 8 & $0<k<0.12$ & 20 & $0.89<d<1$ \\
\hline 100 & 0.9 & 9 & $0<k<0.12$ & 21 & $0.89<d<1$ \\
\hline 1000 & 0.1 & 10 & $0<k<0.08$ & 22 & $0.92<d<1$ \\
\hline 1000 & 0.5 & 11 & $0<k<0.08$ & 23 & $0.92<d<1$ \\
\hline 1000 & 0.9 & 12 & $0<k<0.08$ & 24 & $0.92<d<1$ \\
\hline
\end{tabular}

As seen from Table 1 , the $k$ and $d$ intervals enlarge as correlation values increases for sample sizes $n=30$ and 60 . However, when sample sizes $n$ increases the $k$ and $d$ intervals are not affected from different correlation values for the same sample size. This situation arises from the structure of $M S E$ matrices. MSE matrices are known as: $M S E=$ Variance $+(\text { Bias })^{2}, M S E$ matrices are just equal to the variance of the related estimator for unbiased estimators.

Briefly, when the sample size $n$ increases the amount of bias in the structure of MSE matrix decreases. Hence, the increasing of the correlation coefficient has not much effect on the $k$ and $d$ intervals as seen from Table 1 . 
As a result, as the sample size $\mathrm{n}$ increases, the bias related to the biased estimator existing in the structure of $M S E$ matrices will decrease. Thus, as it can be noticed by looking at Table 1, despite of the increasing correlation coefficient, the $k$ and $d$ intervals are not differ, which satisfy the appropriate values of Ridge and Liu estimators.

\section{CONCLUSION}

Ebegil et. al. compare a simulation study with $n=50$ and different correlation coefficients to obtain optimal $k$ and $d$ intervals for the Ridge and Liu estimators, respectively [7]. In this study we also compare these estimators for the general case under different correlation coefficients between the independent variables and different sample sizes with the help of a simulation study.

In conclusion, we found that small sample sizes and large correlation values the interval of $\mathrm{k}$ and $\mathrm{d}$ enlarged, in which the using of the biased estimators gives better results than LS estimators. On the other hand, when the sample sizes increase the amount of bias in the structure of $M S E$ matrices decrease and the correlation values among independent variables has no effect on the intervals. This means that using biased estimators is more appropriate than using LS estimators.

ÖZET: Regresyon analizinde, bağımsız (açıklayıcı) değişkenler arasında ilişki (çoklu bağlantı) olması durumunda, En Küçük Kareler (EKK) tahmin yönteminin kullanılması yanlış model bulgularına, dolayısıyla yanlış modellemeye neden olur. Birbirleriyle bağımlılık gösteren bu tür bağımsız değişkenlerle analiz yapmak için geliştirilen yöntemlerden bir tanesi de yanlı tahmin yöntemleridir. Bu çalışmada, yanlı tahmin ediciler içinde yer alan Shrinkage tahmin edicilerinden Ridge ve Liu tahmin edicileri ile EKK tahmin edicisinden birini tercih etmek için bir test istatistiği özetlenmiştir. Bu test istatistiğinden yararlanarak, Ridge ve Liu tahmin edicilerinin EKK tahmin edicisine göre tercih edildiği değer aralıkları, farklı korelasyon yapılarında ve farklı örnek çaplarında ne tür değişiklikler gösterebilecekleri simülasyon yoluyla incelenmiş ve karşılaştırmalar yapılmıştır.

Anahtar Kelimeler: Doğrusal Kabul Edilebilir Tahmin Ediciler; Ortalama Hata Kare; Merkezi-F Yaklaşımı; Shrinkage Tahmin Ediciler

\section{REFERENCES}

[1] Farebrother, R. W., A Class of Shrinkage Estimators, J. R. Statist. Soc. B, 40 (1978), 47-49.

[2] Liski,E.P., A Test of the Mean Square Error Criterion for Shrinkage Estimators. Communications in Statistics 11(5), (1982), 543-562.

[3] Liski,E.P., Choosing a Shrinkage Estimator-a test of the Mean Square Error Criterion. Proc. First Tampere Sem. Linear Models, (1983), 245-262. 
[4] Kejian,L.,A New Class of Biased Estimate in Linear Regression.Com.Statist.-Theory Meth.,22(2).(1993), 393-402.

[5] Akdeniz, F. and Kaçıranlar, S., On the Almost Unbiased Generalized Liu Estimator and Unbised Estimation of the Bias and MSE. Commun. Statist-Theory and Meth., 24(7), (1995), 1789-1797.

[6] Akdeniz,F. and Erol, H., Mean Squared Error Matrix Comparisons of Some Biased Estimators in Linear Regression. Communications in Statistics-Theory And Methods, 32, (2003), 23892413

[7] Ebegil, M.,Gökpınar, F. and Ekni, M., A Simulation Study on Some Shrinkage Estimators, Hacettepe Journal of Mathematics and Statistics, 35(2), (2006), 213-226.

[8] Toutenburg, H., Prior Information in Linear Models., John Wiley and Sons. New York,(1982).

[9] Theobald, C. M., Generalizations of Mean Square Error Applied to Ridge Regression.J.R.Statist.Soc.,B,36, (1974), 103-106.

[10] Rao, C. R. , Estimation of Parameters in a Linear Model. The Annals of Statistics 4, (1976), 1023-1037.

[11] Searle S. R. , Matrix Algebra Useful for Statistic, John Wiley and Sons., New York, (1982).

12] Norman, L. J. and Samuel, K., Distributions in Statistics, Chapter 26, (1970).

[13] Patnaik, P. B., The Noncentral Ki-kare and F Distributions and their Applications, Biometrika 36, (1949), 202-232.

Current address: Department of Statistics, Faculty of Science and Arts, University of Gazi, Beşevler, 06500, Ankara, Turkey

E-mail address: mdemirel@gazi.edu.tr 